\title{
Behind the Manufacturing of Industrial Clay Bricks: Drying Stage Predictions Using CFD
}

\author{
R. S. Santos, ${ }^{1}$ J. M. P. Q. Delgado ${ }^{\circ},{ }^{2}$ F. A. N. Silva $\mathbb{D}^{\circ},{ }^{3}$ A. C. Azevedo $\triangle{ }^{2},{ }^{2}$ S. R. Farias Neto ${ }^{\circ},{ }^{4}$ \\ F. P. M. Farias $\mathbb{D}^{\mathbb{D}},{ }^{5}$ A. G. Barbosa de Lima $\mathbb{D}^{\circ},{ }^{6}$ W. M. P. Barbosa de Lima $\mathbb{D}$, ${ }^{6}$ and E. S. Lima $\mathbb{D}^{6}$ \\ ${ }^{1}$ Rural Federal University of Semi-Arid (UFERSA), Caraúbas, Rio Grande do Norte, Brazil \\ ${ }^{2}$ CONSTRUCT-LFC, Department of Civil Engineering, Faculty of Engineering, University of Porto, Porto, Portugal \\ ${ }^{3}$ Department of Civil Engineering, Universidade Católica de Pernambuco, Recife, Brazil \\ ${ }^{4}$ Department of Chemical Engineering, Federal University of Campina Grande, Paraiba, Campina Grande, Brazil \\ ${ }^{5}$ Department of Technology of the Development, Federal University of Campina Grande, Sumé, Paraiba, Brazil \\ ${ }^{6}$ Department of Mechanical Engineering, Federal University of Campina Grande, Paraiba, Campina Grande, Brazil
}

Correspondence should be addressed to J. M. P. Q. Delgado; jdelgado@fe.up.pt

Received 3 February 2021; Revised 13 January 2022; Accepted 9 February 2022; Published 1 March 2022

Academic Editor: Davide Palumbo

Copyright (C) 2022 R. S. Santos et al. This is an open access article distributed under the Creative Commons Attribution License, which permits unrestricted use, distribution, and reproduction in any medium, provided the original work is properly cited.

\begin{abstract}
Drying of ceramic materials plays important role for industry, involving questions related to investments, energy consumption, product quality, and environmental pollution. In this sense, this work aims to predict heat and mass transfer during the drying process of an industrial clay brick in oven. Simulations were carried out by computational fluid dynamics (Ansys CFX software). Results of the drying and heating kinetics and the moisture content and temperature distributions of the product at different elapsed times are shown and analyzed. The results showed a good agreement between the experimental data, of the surface temperature and the average moisture content, and the numerical results. From the results, it was verified that the proposed mathematical modeling was adequate, providing predicted results in accordance with the experimental data used. Furthermore, numerical results showed that an increase in drying-air temperature and a decrease in relative humidity lead to an increase in heating and moisture removal rates. In the research, it was observed that mass diffusion coefficient increased with increasing drying-air temperature.
\end{abstract}

\section{Introduction}

Ceramic can be defined as any nonmetallic and inorganic material whose structure, after heat treatment at high temperatures, is wholly or partially crystallized. These materials are well known to have different raw materials in their composition, mainly clay. Clay is an earthy, thin, and natural material that has an important characteristic: when mixed in water, it acquires plasticity and can be easily molded at different shapes $[1,2]$.

Manufacturing of clay products involves different steps, such as raw material treatment, homogenization, molding, drying, and firing. Drying is one the most important steps, being responsible for great part of the energy consumption and quality of the product that will be used in the step of the processing: the firing. It is well known that during the drying process, there are several changes in the characteristics of a clay product, namely, physical, chemical, and of geometry, provoked by simultaneous thermal and hydric effects. Thus, it is very important to adequately control the process variables, in order to minimize deterioration and improve product quality after drying.

In general, several studies related to drying of clay material have been realized by experiments [3-6] and simulations [7-16]. For drying predictions, mathematical models based on Fick's and Fourier's laws of diffusion have been frequently used for different materials, considering heat and mass transfer mechanisms, initial moisture content and temperature, volumetric variations, and external environmental conditions $[17,18]$. 
Vasconcelos da Silva et al. [5] reported one experimental research about drying of industrial clay bricks in oven at different drying-air conditions. According to the authors, clay is basically composed of silica and alumina, and drying at high temperature and low relative humidity of the air generates high moisture removal, heating, and volumetric variation rates in the ceramic product.

da Silva et al. [7] presented a theoretical (Fick's second law of diffusion) and experimental study about drying of clay slabs at different temperatures. According to the authors, the model considering variable mass diffusion coefficient proved to be most appropriated to describe the process at all drying conditions used.

Prediction studies of a specific physical problem encompass many useful aspects at the academic and industrial point of views. They present possibility to accept or reject hypothesis related to the systems, to reveal contradictions in obtained data and/or formulated hypothesis, and to help in predicting the system behavior and steady or transient state under conditions tested or none, in laboratory. This way, it is possible to optimize the process, to increase product quality after process, and to reduce process cost. The idea is to control the system efficiency, monitoring the process variables using appropriated iterative software developed by own user or by companies (commercial software).

Computational fluid dynamics (CFD) simulations have been used with success at different fields, having shown to be a powerful technique in the analysis of different physical and chemical problems. However, research studies involving brick drying using CFD analysis are scarce and, in general, devoted to specific geometries [12-16].

Araújo et al. [15] studied the convective drying process in an industrial hollow clay brick inside the oven. The process analysis was done using a computational fluid dynamics technique, and the variables, air in the oven and water mass and temperature fields within the industrial hollow, are shown and analyzed along the drying process.

As a complement to these research studies, this article aims to study heat and mass transport in an industrial clay brick during drying process using CFD. Herein emphasis is given to an industrial block produced in Brazil and commonly used in building construction. The work focuses on the convective heat and mass transfer phenomena at the surface of the brick and diffusive heat and mass transfer within the wet product. Innovative aspects of this research are related in evaluating the effect of the drying conditions on the heating and moisture removal processes with the aims of estimating the heat and mass transport coefficients involved in the drying process.

\section{Methodology}

2.1. The Geometry and the Physical Problem. In this numerical work, it was used one wet clay brick at low temperature surrounded by hot air flowing around it (see Figure 1). This way, heat is supplied to the brick by convection, provoking moisture removal and heating of the product. The dimensions and mineralogical composition

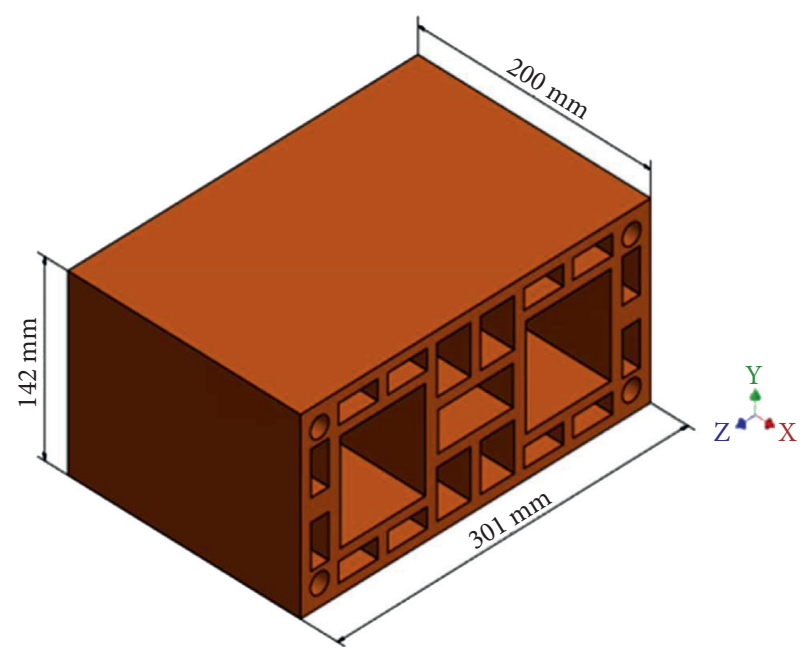

FIGURE 1: Schematic representation of the industrial clay brick used in this research.

and chemical of the brick are equal to that used by Silva et al. [5].

A schematic representation of the industrial clay brick used in this work, built using the ICEM CFD software (the grid), is presented in Figure 2. After grid and time step refinement studies and based on the computational cost and accuracy in the results, it was chosen one grid with 169.940 elements and 198.120 nodes. The grid refinement was carried out based on the grid convergence index as reported by Celik [19]. Information about the mesh refining procedure will be given later.

2.2. Mathematical Modeling. The mathematical model developed was based on several assumptions: (a) it was considered that all the water migrates in the liquid phase and it was evaporated at the surface; (b) the heat flux is transferred in the interior of the material by conduction and at the surface by convection; (c) the internal mass and the heat generation are neglected; (d) the volume variations are disregarded; (e) thermo-physical properties were assumed constant; and (e) it was considered that for every face of the solid, the convective mass and heat transfer coefficients are constant.

In order to describe the drying process of the brick, the following equations were used [20]:

(a) Mass conservation equation: the mass transport equation of water mass inside the solid with an additional variable, taking into account the solid domain without motion, is given by

$$
\frac{\partial M}{\partial t}=\nabla \cdot\left(D_{s} \nabla M\right),
$$

where $M$ is the moisture content (dry basis) inside the porous material at time $t(\mathrm{~s})$ and $D_{s}$ is the diffusion coefficient $\left(\mathrm{m}^{2} / \mathrm{s}\right)$.

(b) Energy conservation equation: the heat transfer equation applied to the wet brick is given as follows: 

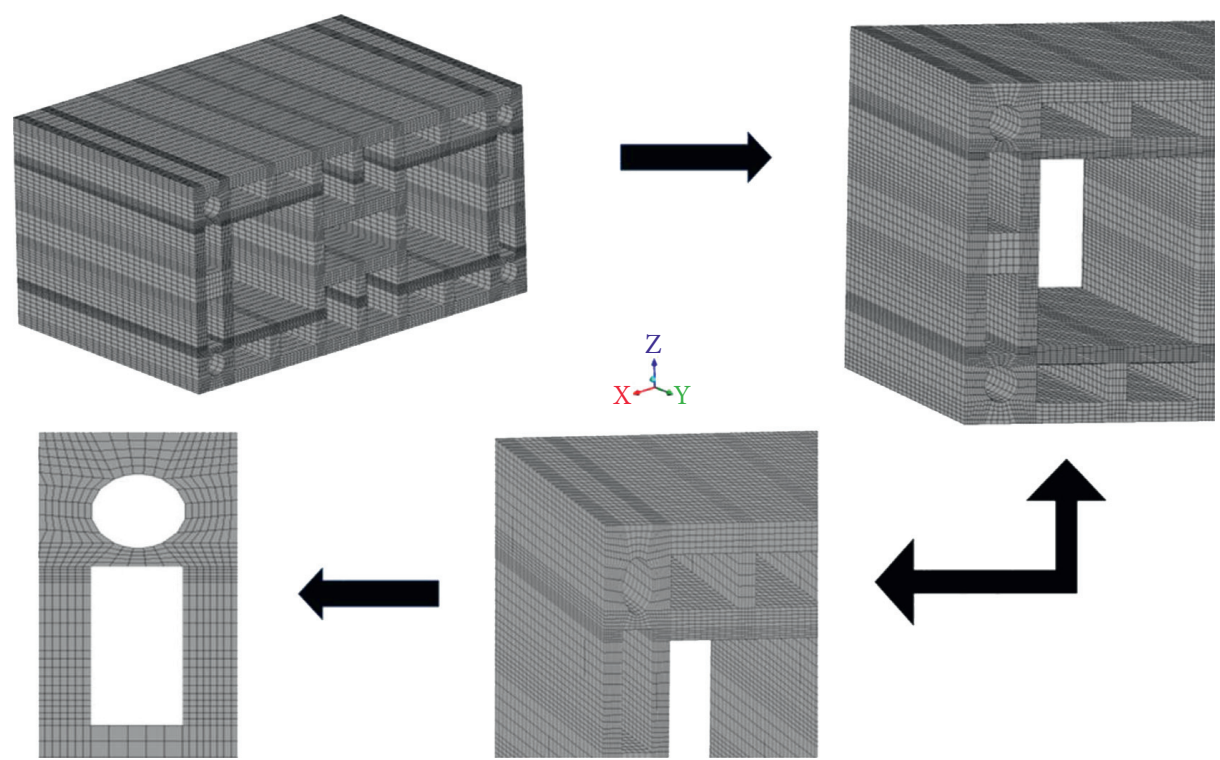

FIGURE 2: Computational representation of the industrial clay brick used in this research.

$$
\frac{\partial}{\partial t}\left(\rho_{s} H_{s}\right)=\nabla \cdot\left(\lambda_{s} \nabla T_{s}\right),
$$

where $\rho_{s}$ is the specific mass $\left(\mathrm{kg} / \mathrm{m}^{3}\right), H_{s}$ is the enthalpy $(\mathrm{J} / \mathrm{kg}), \lambda_{s}$ is the thermal conductivity $(\mathrm{W} / \mathrm{m} . \mathrm{K})$, and $T_{s}$ is the temperature inside the brick $\left({ }^{\circ} \mathrm{C}\right)$.

The average value of the variable in studying moisture content or temperature in each instant of drying was determined by

$$
\bar{\Phi}=\frac{1}{V} \int_{V} \Phi \mathrm{d} V
$$

where $F$ can be $M$ or $T$ and $V$ is the volume of the brick.

2.3. Initial and Boundary Conditions. To simulate correctly the drying process, the initial and boundary conditions of the porous brick were appropriately chosen. The initial conditions are as follows: the initial temperature $\left(T_{0}\right)$, the initial water mass $\left(m_{0}\right)$, and the boundary conditions are as follows:

(a) For mass transfer at the solid surface, the diffusive mass flux of a substance is equal to the convective mass flux in the air:

$$
-D_{s} \nabla \mathrm{M}=h_{m}\left(M-M_{e q}\right),
$$

where $M$ is the instantaneous moisture content at the surface (dry basis); $M_{e q}$ is the moisture content at equilibrium condition; and $h_{m}$ is the convective mass transfer coefficient $(\mathrm{m} / \mathrm{s})$.

(b) For the heat transfer at the solid surface, the diffusive heat flux is equal to the convective heat flux:

$$
-\lambda_{s} \nabla \mathrm{T}=h_{c}\left(T_{e}-T\right)
$$

where $\lambda_{s}$ is the thermal conductivity; $T$ is the temperature at the interface at time $t ; T_{e}$ is the temperature at thermal equilibrium; and $h_{c}$ is the convective heat transfer coefficient $\left(\mathrm{W} / \mathrm{m}^{2} \mathrm{~K}\right)$.

\section{Experimental Procedure}

In this work, the experimental data obtained by Vasconcelos da Silva et al. [5] were used. The experimental procedure used to obtain the experimental data of [5] was described in detail in [21]. Figures 3 and 4 show an example of the ceramic brick used in this work and a sketch of the material with points used for temperature measurement, respectively. Tables 1 and 2 present the experimental data used in the numerical simulations.

Tables 1 and 2 describe the experimental conditions of the ceramic brick and drying-air used in the experiment.

\section{Numerical Procedure}

4.1. Transport Coefficient Estimation. The numerical simulations, by computational fluid dynamics (Ansys CFX software), were performed in a transient state, with a time step of 10 minutes and a mean square residue of $10^{-6}$.

The thermal properties of the brick are shown in Table 3.

In this research, a rigorous statistical treatment was performed, which allowed estimating the best effective mass diffusion coefficient and convective heat and mass transfer coefficient. This procedure was performed using the least square error (ERMQ) and the variance $S^{2}$ as statistical parameters of analysis, given by

$$
\begin{aligned}
\text { ERMQ } & =\sum_{i=1}^{n}\left(\varnothing_{i, \text { num }}-\varnothing_{i, \text { exp }}\right)^{2}, \\
\bar{S}^{2} & =\frac{\text { ERMQ }}{(n-\hat{n})},
\end{aligned}
$$




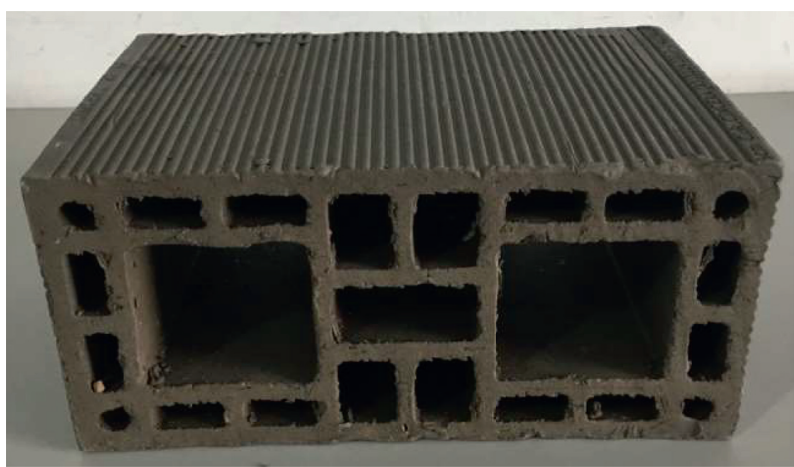

FIgURE 3: Example of the ceramic brick used.

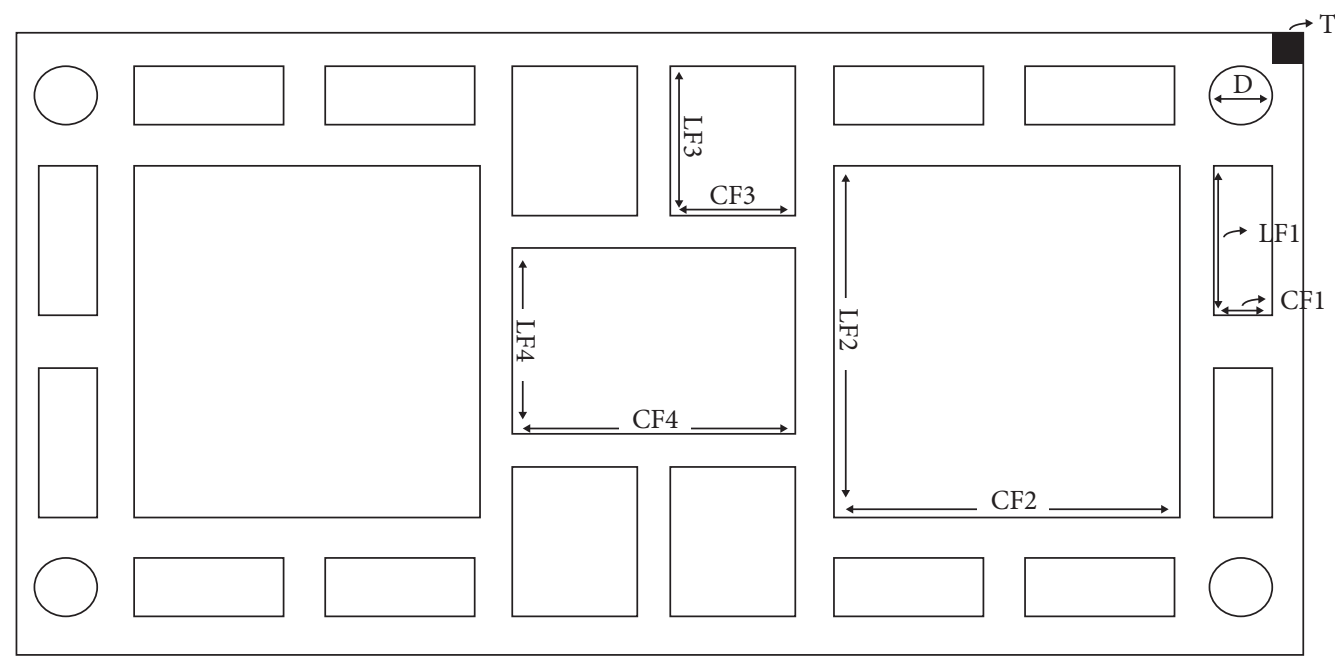

FIGURE 4: Sketch of the ceramic brick used highlighting the point used for temperature measurement.

TABLE 1: Values used in numerical simulations with a ceramic brick (geometrical data).

\begin{tabular}{lcccccccc}
\hline D $(\mathrm{mm})$ & $\mathrm{CF} 1(\mathrm{~mm})$ & $\mathrm{LF} 1(\mathrm{~mm})$ & $\mathrm{CF} 2(\mathrm{~mm})$ & LF2 $(\mathrm{mm})$ & $\mathrm{CF} 3(\mathrm{~mm})$ & LF3 $(\mathrm{mm})$ & $\mathrm{CF} 4(\mathrm{~mm})$ & LF4 $(\mathrm{mm})$ \\
\hline 15.1 & 15.3 & 33.0 & 71.6 & 71.8 & 35.6 & 25.8 & 30.1 & 61.2 \\
\hline
\end{tabular}

TABLE 2: Values used in numerical simulations with a ceramic brick (experimental conditions).

\begin{tabular}{|c|c|c|c|c|c|c|c|c|}
\hline \multirow{2}{*}{ Case } & \multicolumn{4}{|c|}{ Brick } & \multicolumn{3}{|c|}{ Air } & \multirow{2}{*}{$t(\min )$} \\
\hline & $M_{o}(\mathrm{~kg} / \mathrm{kg})$ & $M_{e}(\mathrm{~kg} / \mathrm{kg})$ & $T_{o}\left({ }^{\circ} \mathrm{C}\right)$ & $T_{e}\left({ }^{\circ} \mathrm{C}\right)$ & $T\left({ }^{\circ} \mathrm{C}\right)$ & $\mathrm{RH}(\%)$ & $v(\mathrm{~m} / \mathrm{s})$ & \\
\hline 1 & 0.172319 & 0.002685 & 31.5 & 50 & 50 & 18.39 & 1.0 & 1170 \\
\hline 2 & 0.173163 & 0.001834 & 32.0 & 60 & 60 & 12.27 & 1,0 & 1050 \\
\hline 3 & 0.170186 & 0.001189 & 29.8 & 70 & 70 & 7.72 & 1.0 & 990 \\
\hline 4 & 0.172723 & 0.000826 & 30.5 & 80 & 80 & 4.99 & 1.0 & 930 \\
\hline 6 & 0.167900 & 0.000511 & 27.6 & 90 & 90 & 3.56 & 1.0 & 930 \\
\hline 7 & 0.169366 & 0.000054 & 27.5 & 100 & 100 & 2.34 & 1.0 & 750 \\
\hline
\end{tabular}

TABLE 3: Thermal properties of the clay brick.

\begin{tabular}{lcr}
\hline Properties & Clay & Reference \\
\hline Thermal conductivity $\lambda_{s}\left(\mathrm{~W} \mathrm{~m}^{-1} \mathrm{k}^{-1}\right)$ & 1675.0 & {$[20]$} \\
Specific heat $C_{p}\left(\mathrm{~J} \mathrm{~kg}^{-1} \mathrm{k}^{-1}\right)$ & 1673.0 & {$[22]$} \\
Density $\rho\left(\mathrm{kg} / \mathrm{m}^{3}\right)$ & 1985.8 & {$[22]$} \\
\hline
\end{tabular}


where $n$ is the number of experimental data, $\widehat{n}$ is the number of fitted parameters (number of degrees of freedom), $\varnothing i$, num is the numerical value, and $\varnothing i$, exp is the experimental value.

Furthermore, one statistical treatment based on the t-Student and Pearson correlations, in order to verify the statistical significance of the difference between the experimental and predicted values and the confidence intervals, was realized.

The least square error technique follows the steps:

(a) Guessed values of $h_{m}$ and $D$ are used in the first simulation and the ERMQ calculated.

(b) Fix $h_{m}$, correction in the effective mass diffusion coefficient is done, new simulation is performed, and ERMQ is calculated again. If the new value of ERMQ is lower than the old value, new correction is done in $D_{s}$, and the numerical procedure continues until $\mathrm{ERMQ}_{\text {new }}>\mathrm{ERMQ}_{\text {old }}$.

(c) The best $D_{s}$ obtained in step "b" is fixed, correction in the convective mass transfer coefficient is done, new simulation is performed, and ERMQ is calculated again. If the new value of ERMQ is lower than the old value, new correction is done in $h_{m}$, and the numerical procedure continues until $\mathrm{ERMQ}_{\text {new }}>\mathrm{ERMQ}_{\text {old }}$.

(d) After step "c" is stopped, the best value of $h_{m}$ obtained in the step " $c$ " is fixed and the process returns to step "b".

(e) The process continues until the best values of $h_{m}$ and $D_{s}$ are obtained.

Similar procedure was performed to estimate the convective heat transfer coefficient.

4.2. Mesh Refining Study. For the present work, a mesh convergence study was carried out. This study was carried out for the case studies of brick drying in oven and considering the infinite mass transfer coefficient. The method used here is based on the Richardson extrapolation, which considers that any discrete solution has a series representation. The idea of this method is to estimate the exact solution from the extrapolation of the solutions of the existing meshes and by calculating the convergence index related to the produced meshes. Celik [19] suggests 5 steps to determine the mesh convergence index (ICM) and thus quantify the uncertainties regarding discretization errors and determine the best mesh to be used in the simulations. This procedure is as follows.

Initially, a representative size of the mesh element $\gamma$ was determined by

$$
\gamma=\left[\frac{1}{N} \sum_{i=1}^{N} \Delta V_{i}\right]^{1 / 3},
$$

where $N$ is the number of mesh elements used for the computational calculation and $\Delta V_{i}$ is the volume occupied by element $i$.

From this value determined in the first step, three meshes were generated, so that the ratio $r=\gamma_{\text {coarse }} / \gamma_{\text {refined }}$ was greater than 1.3 for each mesh. In the present work, $\gamma=2.0$ was adopted. The refinement of the meshes was done systematically, that is, meshes with elements of similar formats were used.

Let be $\gamma_{1}$ the finer mesh, $\gamma_{2}$ be the intermediate mesh, and $\gamma_{3}$ be the coarsest mesh. The values $r_{21}$ and $r_{32}$ were defined based on equations (8) and (9).

$$
\begin{aligned}
& r_{21}=\frac{\gamma_{2}}{\gamma_{1}}, \\
& r_{32}=\frac{\gamma_{3}}{\gamma_{2}} .
\end{aligned}
$$

The results of a given variable $\varnothing$ were defined as $\varnothing_{1}, \varnothing_{2}$, and $\varnothing_{3}$ for the meshes M1, M2, and M3, respectively. Then, the apparent order $p$ was determined from equations (11)-(13), which can be solved using any iterative numerical method.

$$
\begin{aligned}
p & =\frac{1}{\ln \left(r_{21}\right)}|\ln | \frac{1}{G}|+q(p)|, \\
q(p) & =\ln \left(\frac{r_{21}^{p}-S}{r_{32}^{p}-S}\right), \\
S & =\operatorname{Signal}\left(\frac{\varepsilon_{32}}{\varepsilon_{21}}\right),
\end{aligned}
$$

where $G=\varepsilon_{21} / \varepsilon_{32}, \varepsilon_{21}=\varnothing_{2}-\varnothing_{1}$, and $\varepsilon_{32}=\varnothing_{3}-\varnothing_{2}$.

To verify the convergence of the solution, equation (14) was used, where $0<C<1$ is an indicator of monotonic convergence, $C<0$ indicates oscillatory convergence, and $C>1$ indicates divergence of the solution [23].

$$
C=\frac{\varnothing_{1}-\varnothing_{2}}{\varnothing_{2}-\varnothing_{3}} \text {. }
$$

To obtain the extrapolated solutions, the following equation was used:

$$
\varnothing_{\mathrm{ext}}^{21}=\frac{\left(r_{21}^{p} \times \varnothing_{1}-\varnothing_{2}\right)}{\left(r_{21}^{p}-1\right)} .
$$

The approximate relative error between the meshes was determined according to equations (16) and (17).

$$
\begin{aligned}
& e_{a}^{21}=\left|\frac{\varnothing_{1}-\varnothing_{2}}{\varnothing_{1}}\right|, \\
& e_{a}^{32}=\left|\frac{\varnothing_{2}-\varnothing_{3}}{\varnothing_{2}}\right| .
\end{aligned}
$$


In this way, the mesh convergence indices (ICM) were determined, as follows:

$$
\begin{aligned}
\mathrm{ICM}_{21} & =\frac{1.25 e_{a}^{21}}{r_{21}^{p}-1}, \\
\mathrm{ICM}_{32} & =\frac{1.25 e_{a}^{32}}{r_{32}^{p}-1} .
\end{aligned}
$$

For correct application of the method, it is necessary to ensure that the meshes are within the asymptotic range. In this way, for cases where the exact solution is not known, Roache [24] has stated that the meshes will be within the asymptotic interval when the following mathematical equation is satisfied:

$$
\mathrm{ICM}_{32} \approx r^{p} \times \mathrm{ICM}_{21}
$$

In the simulations referring to mesh refinement, the data contained in Table 4 were used.

\section{Results and Discussion}

5.1. Mesh Dependency Study. Based on the aforementioned methodology, the numerical data presented in Table 5 were obtained, referring to the number of elements of each mesh produced. For better understanding, the meshes were named $\mathrm{M} 1, \mathrm{M} 2$, and M3, where M1 is the most refined mesh, M2 is the intermediate mesh, and M3 is the coarse mesh. The domain discretization was performed in a structured and uniform manner.

Figure 5 illustrates one of the generated meshes and some details of its refinement. For better visualization, the vertex region was enlarged for each of the meshes. A greater refinement along the border regions of the domain is necessary due to the presence of high gradients of temperature and moisture content, in order to allow obtaining with greater precision the effect of these variables.

It is noteworthy that to carry out the mesh dependence study, the construction of four lines distributed along the brick was considered to analyze the moisture content (Figure 6). For the 1st line, two points were taken whose coordinates are $(0.037 ; 0.1 ; 0.0015)$ and $(0.037 ; 0.1 ; 0.14)$, while for lines 2,3 , and 4 , these points have the following coordinates: $(0.1455 ; 0.1 ; 0.0015)$ and $(0.1455 ; 0.1 ; 0.14)$, $(-0.037 ; 0.1 ; 0.0015)$ and $(-0.037 ; 0.1 ; 0.14)$, and $(-0.1455$; $0.1 ; 0.0015)$ and $(-0.1455 ; 0.1 ; 0.14)$, respectively.

Table 6 presents the results obtained with the mesh convergence study for the variable average moisture content at the indicated moments of drying. Upon analyzing the results, it can be observed that the value of $\mathrm{C}$ is also between 0 and 1 . Therefore, it can be said that this variable converges in a monotonic way. Comparing the values of $r^{p} \mathrm{ICM}_{21}$ and $\mathrm{ICM}_{32}$ it can be seen that they are not close, leading to the conclusion that the extrapolated solution is not so close to the exact solution. It can also be observed that the values of $\mathrm{ICM}_{21}$ and $\mathrm{ICM}_{32}$, at the time of $10 \mathrm{~min}$, are not within the asymptotic range of $10 \%$, as indicated by Karatekin [25]. This can be explained by the high moisture content gradients that occur at the beginning of drying. There is also a decrease in the value of $\mathrm{ICM}_{21}$ compared to $\mathrm{ICM}_{32}$, which indicates that the solution approaches the exact solution independent of the mesh for this variable, as was observed too for the temperature variable.

In the global analysis, the value of the apparent order $p$ calculated for each point (time instant) varied between 0.907 and 6.67, and it presented an overall mean of 4.72. There was a monotonic convergence in all the calculated points. In this work, the following was obtained: an average value of the $\mathrm{ICM}_{21}$ of $1.65 \%$, with a maximum value of $2.53 \%$ at the final moment of the process, and an average $\mathrm{ICM}_{32}$ of $3.19 \%$ with a maximum value of $4.44 \%$ at the same time. Comparing the results obtained, there was a reduction in the values of the $\mathrm{ICM}_{21}$ compared to the $\mathrm{ICM}_{32}$ in $97 \%$ of the points. On the other hand, $\mathrm{ICM}_{21}$ was higher than $\mathrm{ICM}_{32}$ in only $3 \%$ of the points, which indicates greater independence of the results in relation to the mesh for the variable moisture content over time. Therefore, it can be affirmed that both the meshes M1 and M2 presented solutions totally independent of the mesh, since the two meshes presented ICM within the asymptotic interval of $10 \%$, according to the limit determined in a study carried out by Karatekin [25]. Thus, taking into account the computational time and cost, M2 mesh was chosen for the simulations.

5.2. Drying Analysis. The numerical results of the drying kinetics of the clay brick obtained at different drying-air conditions and the comparison with the experimental data are presented in Figure 7. Upon analyzing this figure, it can be seen that the average moisture content is exponentially reduced until reaching the equilibrium condition at the end of the process. This behavior is verified for all experiments. Furthermore, it can be seen that the predicted results are in concordance with the experimental data, presenting small differences in some specific points, which leads to the reliability of the methodology applied here. In general way, the higher the drying-air temperature, the higher the drying rate. Thus, the equilibrium condition can be reached in shorter elapsed time, when higher temperature is used for drying purpose (Figure 7).

Figure 8 shows a comparative analysis between the numerical results of the surface temperature and the experimental data of Vasconcelos da Silva et al. [5] as a function of the drying time. It should be mentioned that the surface temperature was measured in the upper right corner of the brick, with the following $x y z$ coordinates $(-0.142891$, $0.00068,0.134406 \mathrm{~m})$, respectively. The results presented in Figure 8 showed a reasonable difference between the numerical and the experimental results. These differences could be explained by some measurement errors and by the fact that the effect of water evaporation associated to latent energy, at the surface, was neglected. Furthermore, it is verified that the higher the air temperature, the higher the heating rate of the clay brick.

In practice, the heat transferred by the air to the porous body, only by convection, is converted into sensitive heat for heating the clay brick and the water inside it and latent heat for moisture vaporization. For each experimental measurement, 
TABLE 4: Data used in mesh refining study.

\begin{tabular}{lccccccc}
\hline $\mathrm{T}\left({ }^{\circ} \mathrm{C}\right)$ & $D_{\mathrm{s}}\left(\mathrm{m}^{2} / \mathrm{s}\right)$ & $h_{c}\left(\mathrm{~W} /\left(\mathrm{m}^{2}{ }^{\circ} \mathrm{C}\right)\right)$ & $h_{m}(\mathrm{~m} / \mathrm{s})$ & $M_{o}$ (d.b. $)$ & $M_{e}($ d.b. $)$ & $T_{o}\left({ }^{\circ} \mathrm{C}\right)$ & $T_{e}\left({ }^{\circ} \mathrm{C}\right)$ \\
\hline 80 & $9 \times 10-10$ & 1 & $1 \times 10+30$ & 0.172723 & 0.000826 & 30.5 & 80 \\
\hline
\end{tabular}

TABLE 5: Quantitative data of the numerical grids evaluated.

\begin{tabular}{|c|c|c|c|c|}
\hline Grid & Number of elements & Number of nodes & $\gamma$ & Simulation time \\
\hline$\overline{M 1}$ & 419,328 & 472,960 & $2.05353 \times 10^{-3}$ & 1 day 6 h $5 \min 30,959 \mathrm{~s}$ \\
\hline M2 & 169,940 & 198,120 & $2.77533 \times 10^{-3}$ & $11 \mathrm{~h} 58 \mathrm{~min} 9,130 \mathrm{~s}$ \\
\hline M3 & 41,496 & 52,640 & $4.44253 \times 10^{-3}$ & $3 \mathrm{~h} 51 \min 49,988 \mathrm{~s}$ \\
\hline
\end{tabular}

$\gamma$ corresponds to the representative mesh size.

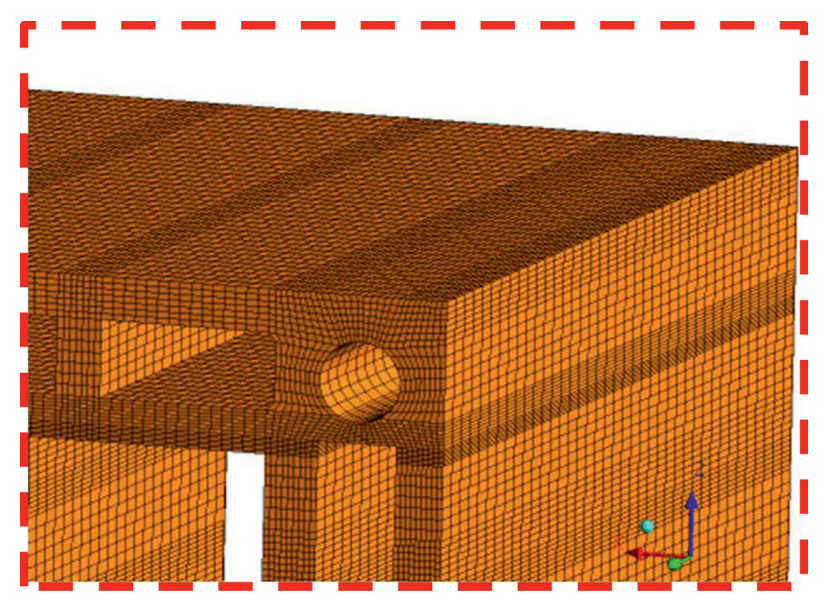

(a)

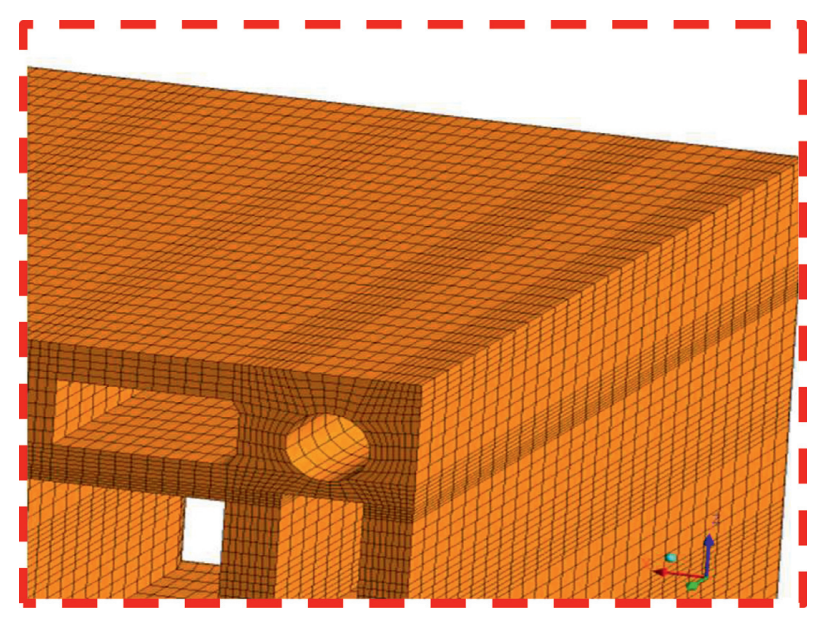

(b)

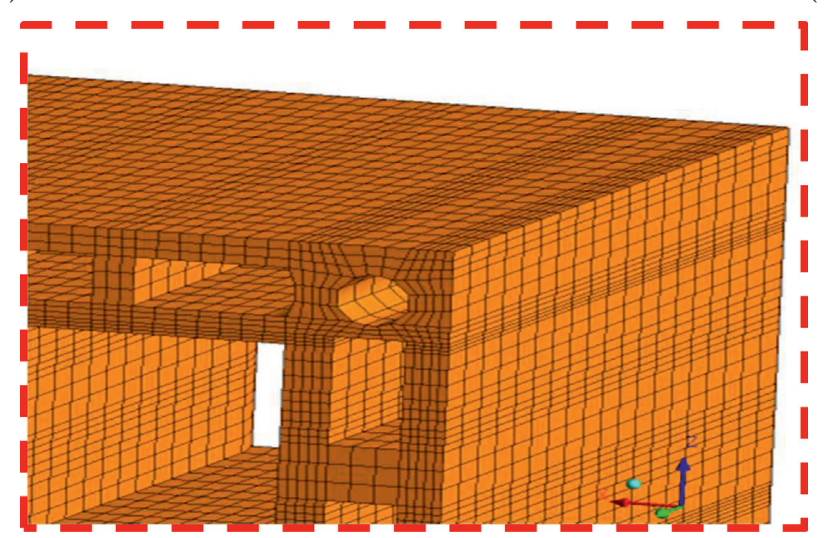

(c)

Figure 5: Representation of the computational mesh of the brick. (a) M1. (b) M2. (c) M3.

the brick was removed from inside the oven. This procedure caused heat loses from the brick surface (that is colder and most humid) to the external air (that is hot and dry), which physical effects were not considered in the mathematical modeling.

This procedure is an explanation for some deviations observed in the graphs; furthermore, it should be mentioned that the temperature measurement was done in the vertex regions of the clay brick, with experimental error associated.

Figure 9 shows the three different positions in $y$ plane $(y=0,0.1$, and $0.2 \mathrm{~m})$ of the longitudinal $X Z$ planes used to analyze in detail the moisture content and temperature behavior inside the clay brick.
In Figures 10-13, the temperature fields inside the clay brick and at the surface are presented, for different times ( $t=10 \mathrm{~min}, 30 \mathrm{~min}, 60 \mathrm{~min}$, and $15.5 \mathrm{~h}$ ). The results showed a very quick increase in the brick surface temperature with time. Moreover, the results also showed that in the center of the clay brick, it is possible to verify, in the beginning, a lower temperature. This value could be explained by the thermal diffusion toward the center of the solid. However, in the border of the brick, the temperature variation is more marked, due to the direct contact of the brick with the hot air flowing over it, with a faster diffusion process. 

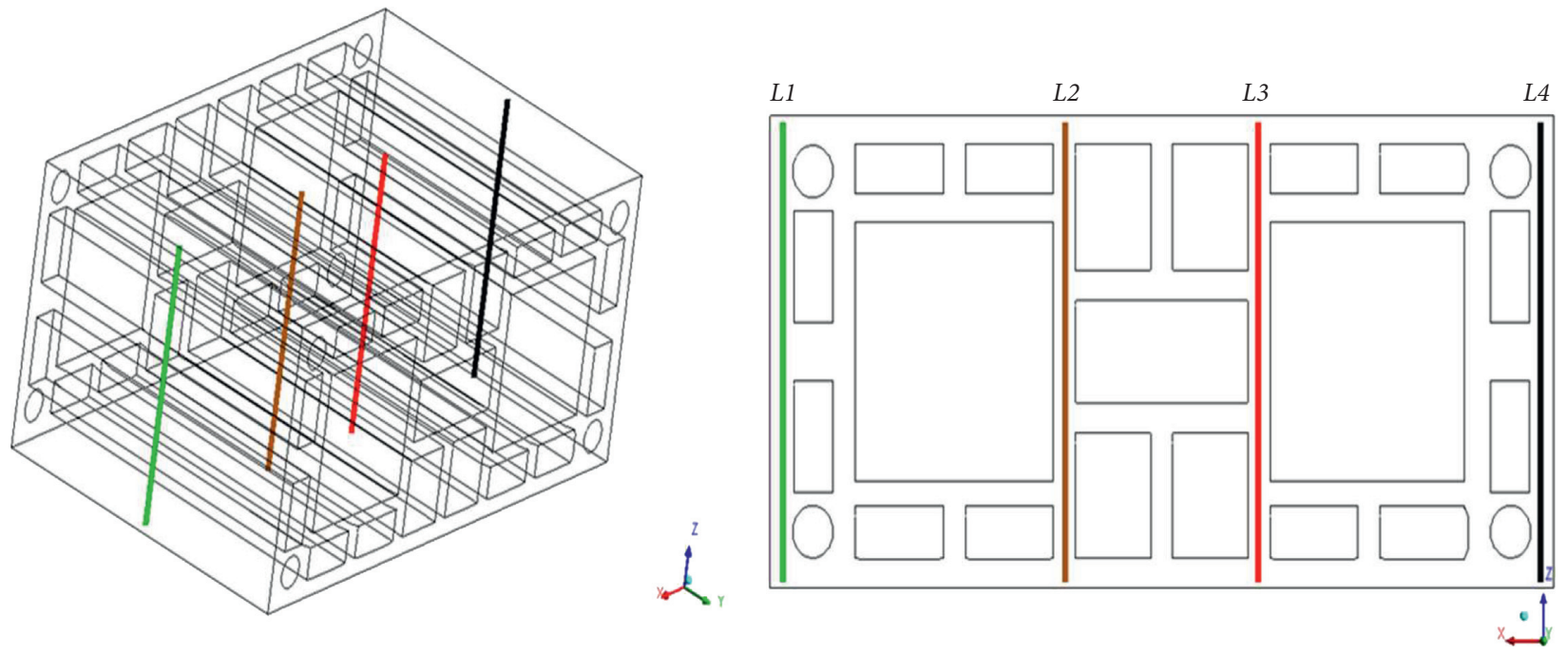

Figure 6: Analysis lines along the brick used in the mesh refining study.

TABLE 6: Mesh convergence parameters for the average moisture content variable.

\begin{tabular}{|c|c|c|c|c|c|c|c|c|c|}
\hline \multirow{2}{*}{$t(\min )$} & \multicolumn{3}{|c|}{$\bar{M}$ (kg/kg, d.b.) } & \multirow{2}{*}{$p$} & \multirow{2}{*}{$\Phi_{\mathrm{ext}}^{21}$} & \multirow{2}{*}{$\mathrm{ICM}_{21}$} & \multirow{2}{*}{$\mathrm{ICM}_{32}$} & \multirow{2}{*}{ C } & \multirow{2}{*}{$r^{p} \mathrm{ICM}_{2}$} \\
\hline & M1 & M2 & M3 & & & & & & \\
\hline 10 & 0.1427 & 0.1472 & 0.1557 & 0.9067 & 0.7403 & 12.8511 & 13.5305 & 0.54 & 16.887 \\
\hline 20 & 0.1258 & 0.1309 & 0.1420 & 1.5775 & 0.6787 & 8.3232 & 9.7324 & 0.45 & 13.386 \\
\hline 30 & 0.1138 & 0.1186 & 0.1306 & 2.0699 & 0.6250 & 6.1283 & 7.7473 & 0.40 & 11.4318 \\
\hline 40 & 0.1043 & 0.1087 & 0.1208 & 2.4860 & 0.5796 & 4.6985 & 6.3460 & 0.36 & 9.9347 \\
\hline 50 & 0.0969 & 0.1003 & 0.1122 & 2.8296 & 0.5393 & 3.7783 & 5.3874 & 0.32 & 8.8602 \\
\hline 60 & 0.0895 & 0.0930 & 0.1046 & 3.1013 & 0.5028 & 3.1941 & 4.7514 & 0.30 & 8.130 \\
\hline
\end{tabular}
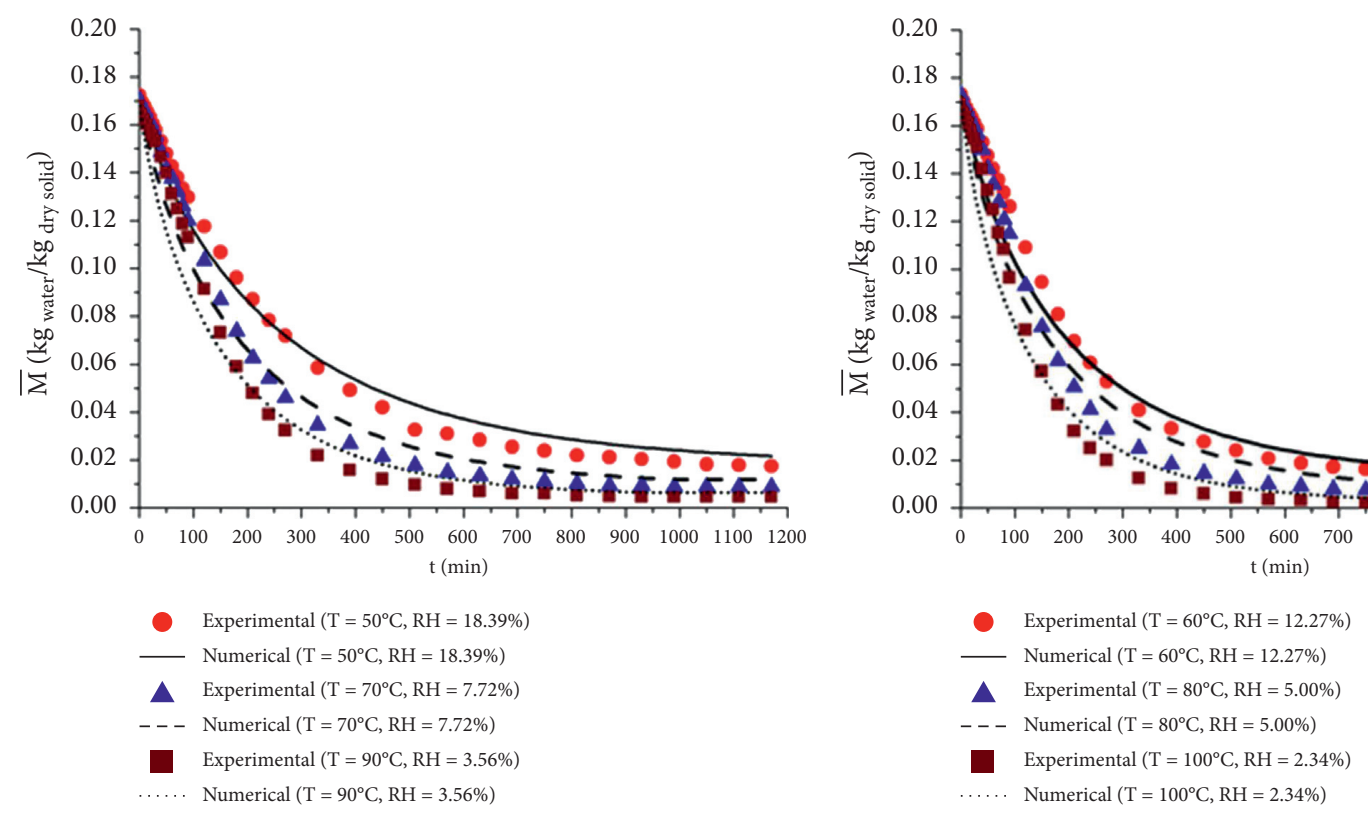

(a)

(b)

Figure 7: Drying kinetics of the industrial clay brick at different drying-air temperatures. (a) $\mathrm{T}=50^{\circ} \mathrm{C}, 60^{\circ} \mathrm{C}$, and $70^{\circ} \mathrm{C}$. $(\mathrm{b}) \mathrm{T}=80^{\circ} \mathrm{C}, 90^{\circ} \mathrm{C}$, and $100^{\circ} \mathrm{C}$.

Figures 14-17 show the moisture content fields at the surface and inside (XZ plans) of the brick at the moments $t=10 \mathrm{~min}, 30 \mathrm{~min}, 60 \mathrm{~min}$, and $15.5 \mathrm{~h}$. Upon analyzing these figures, it is observed that the region, in which the brick drying takes place more quickly, is placed closed to the surface. It is important to notice that this region is also 


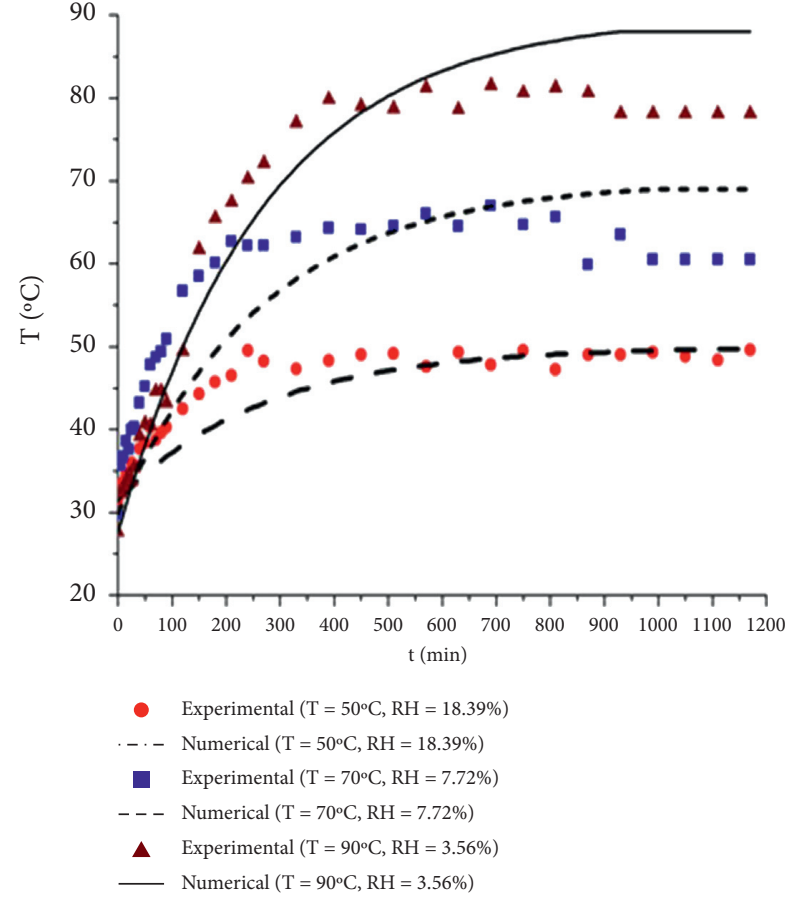

(a)

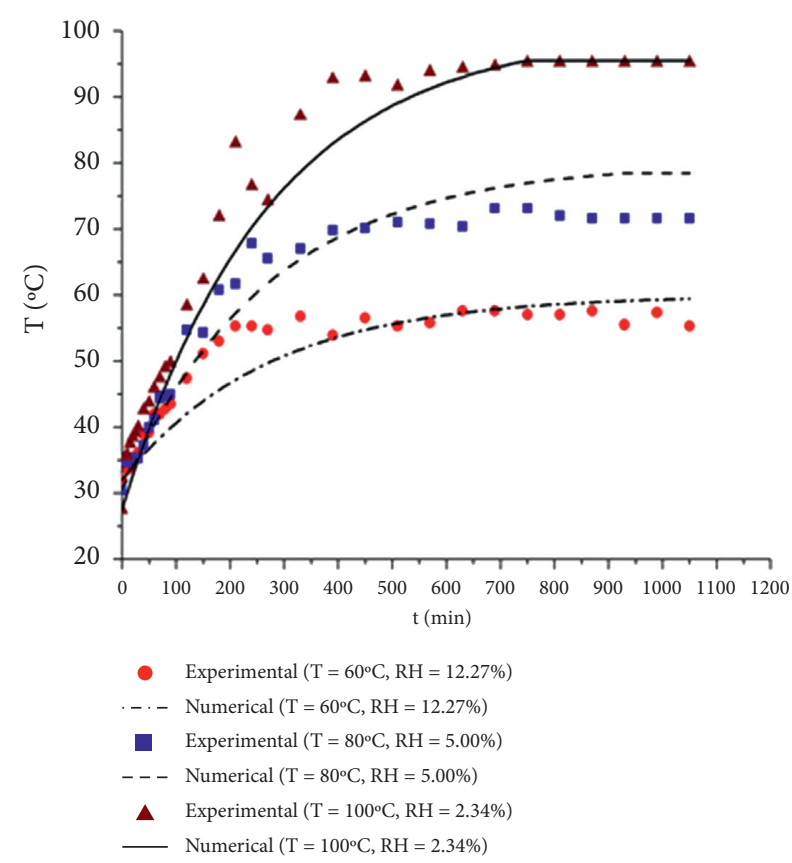

(b)

FIgURE 8: Heating kinetics on the surface of the industrial brick at different drying-air temperatures. (a) $\mathrm{T}=50^{\circ} \mathrm{C}, 60^{\circ} \mathrm{C}$, and $70^{\circ} \mathrm{C}$. (b) $\mathrm{T}=80^{\circ} \mathrm{C}, 90^{\circ} \mathrm{C}$, and $100^{\circ} \mathrm{C}$.

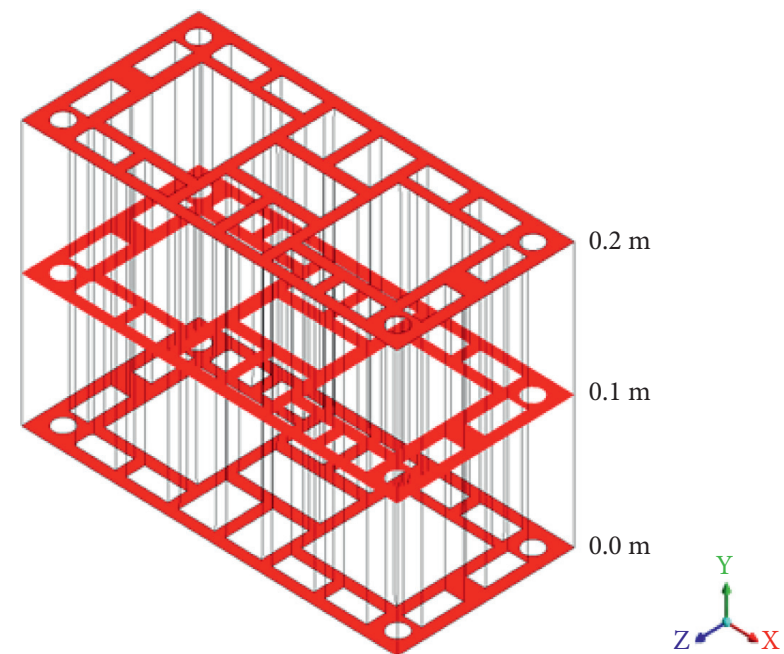

FiguRE 9: Sketch of the three different positions in $y$ plane $(y=0.0$, 0.1 , and $0.2^{\circ} \mathrm{m}$ ) that were used for analysis.

subjected to greater heating. It is verified that the moisture loss is uniform in all surfaces and symmetrical within the brick, provoked by the position of the brick inside the oven and the boundary conditions used in the simulation. It is also noted that the central walls of the material remain wetter. Also, in Figures 14-17, it is verified that parts of brick with minor thickness dry faster than the other ones.

Based on the analysis of Figures 10-17, it is possible to observe that the largest moisture content and temperature gradients are presented near the vertices of the ceramic brick and the smallest temperature and moisture content gradients are presented in the interior of the clay brick. This phenomenon is explained by the fact that the vicinity of the brick near the vertices is in direct contact with the hot air flow. The results also showed that the ceramic brick did not reach the thermal equilibrium after 1 hour of the drying process. Furthermore, temperature variation inside the clay brick is small, in opposition to the moisture content behavior, at any moment during the drying process.

During the process, the regions close to the surface dry and heat faster than the center. Both the physical effects originated thermal and hydric stresses inside the material that are the main causes of different types of defects such as cracks, fissures, and deformation of the product, after drying process. Obviously, defects arising from the molding process must be considered too. These defects can accelerate defects originated by uncontrolled drying, reducing product quality post-drying.

5.3. Transport Coefficient Estimation. As already mentioned, convective heat and mass transport coefficients and effective diffusion coefficients were estimated by equations (6) and (7). Tables 7 and 8 present the transport coefficients obtained by numerical simulations as well as the statistical parameters for each experimental drying condition analyzed. It is possible to verify that the models fitted very well the experimental data, with low values of least square error. Analyzing this table, it can be verified that the mass diffusion coefficient tends to increase with increasing drying-air temperature. 

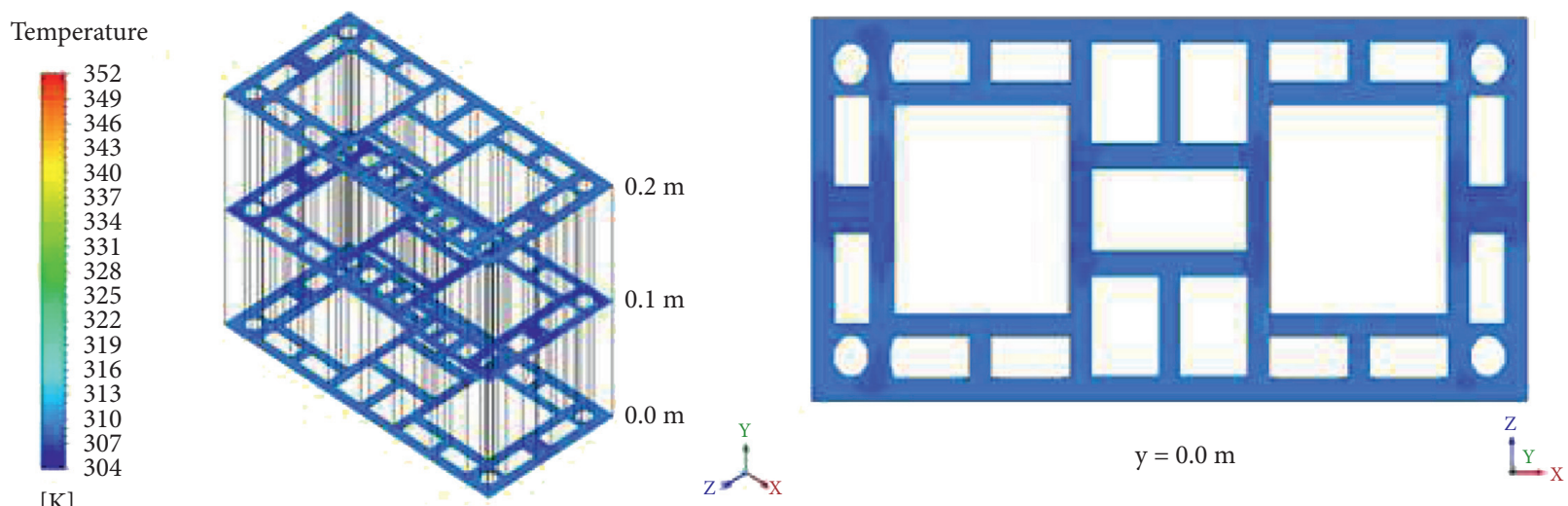

$[\mathrm{K}]$
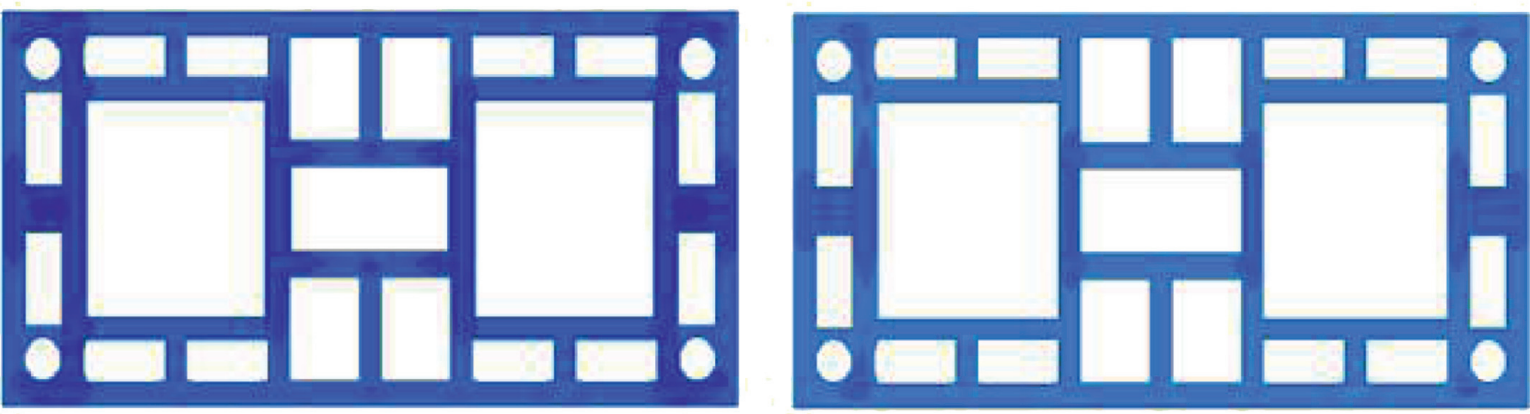

$y=0.1 \mathrm{~m}$
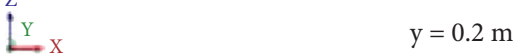

$\stackrel{\mathrm{Y}}{\mathrm{X}}$

Figure 10: Temperature field inside the brick at different $X Z$ planes, with the elapsed time of 10 minutes $\left(T=80^{\circ} \mathrm{C}, \mathrm{RH}=5 \%\right)$.
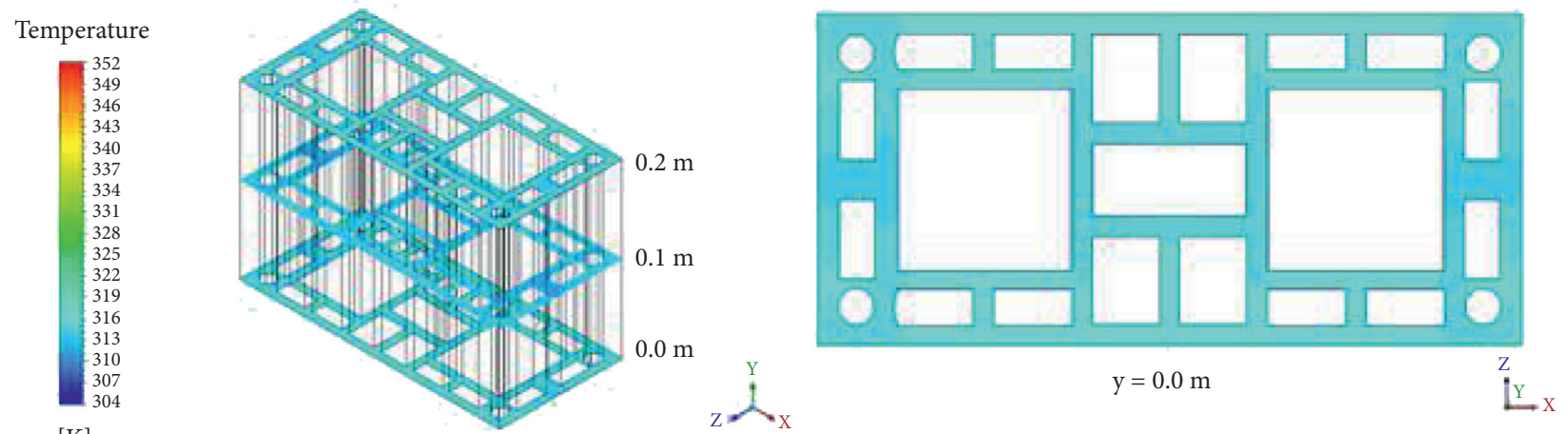

$[\mathrm{K}]$
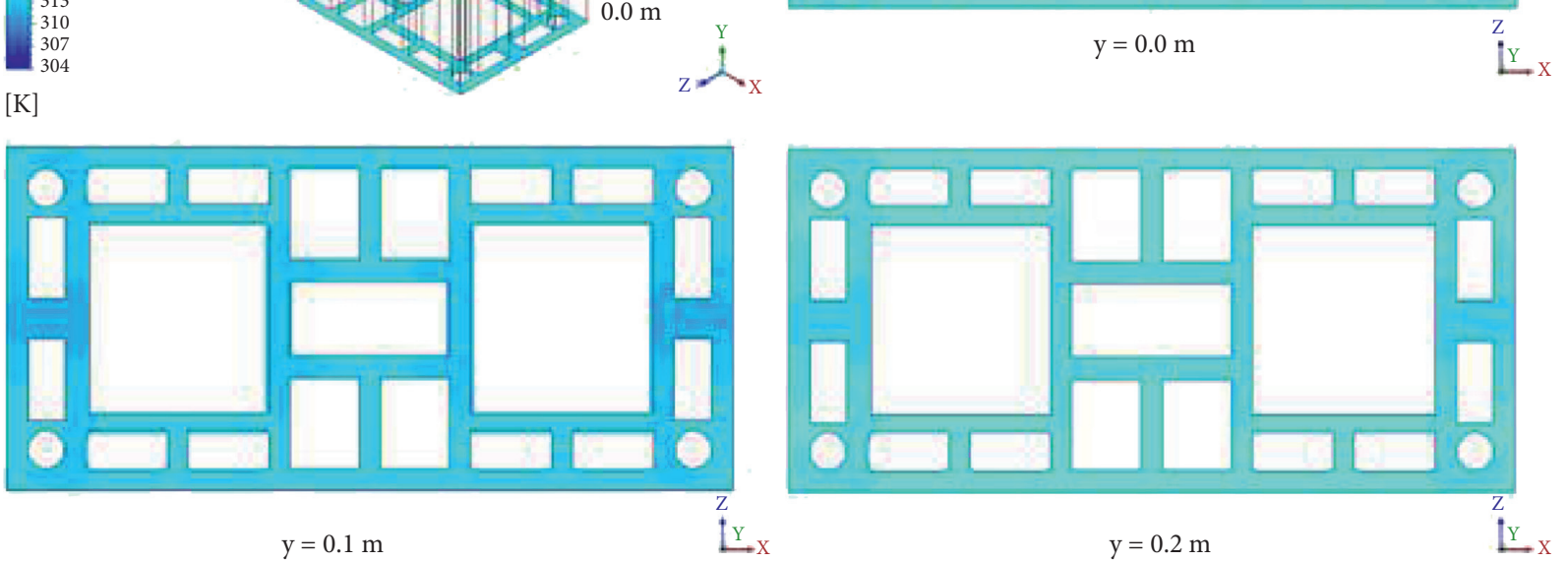

FIgURE 11: Temperature field inside the brick at different $X Z$ planes, with the elapsed time of 30 minutes $\left(T=80^{\circ} \mathrm{C}, \mathrm{RH}=5 \%\right)$.

The comparison of transport coefficient (effective mass diffusion and convective mass transfer) is somewhat complex because the value of this parameter is strongly dependent on several parameters, namely, the material geometric shape, the drying-air conditions, and different nature of the material used (granulometry, clay type, etc.), 

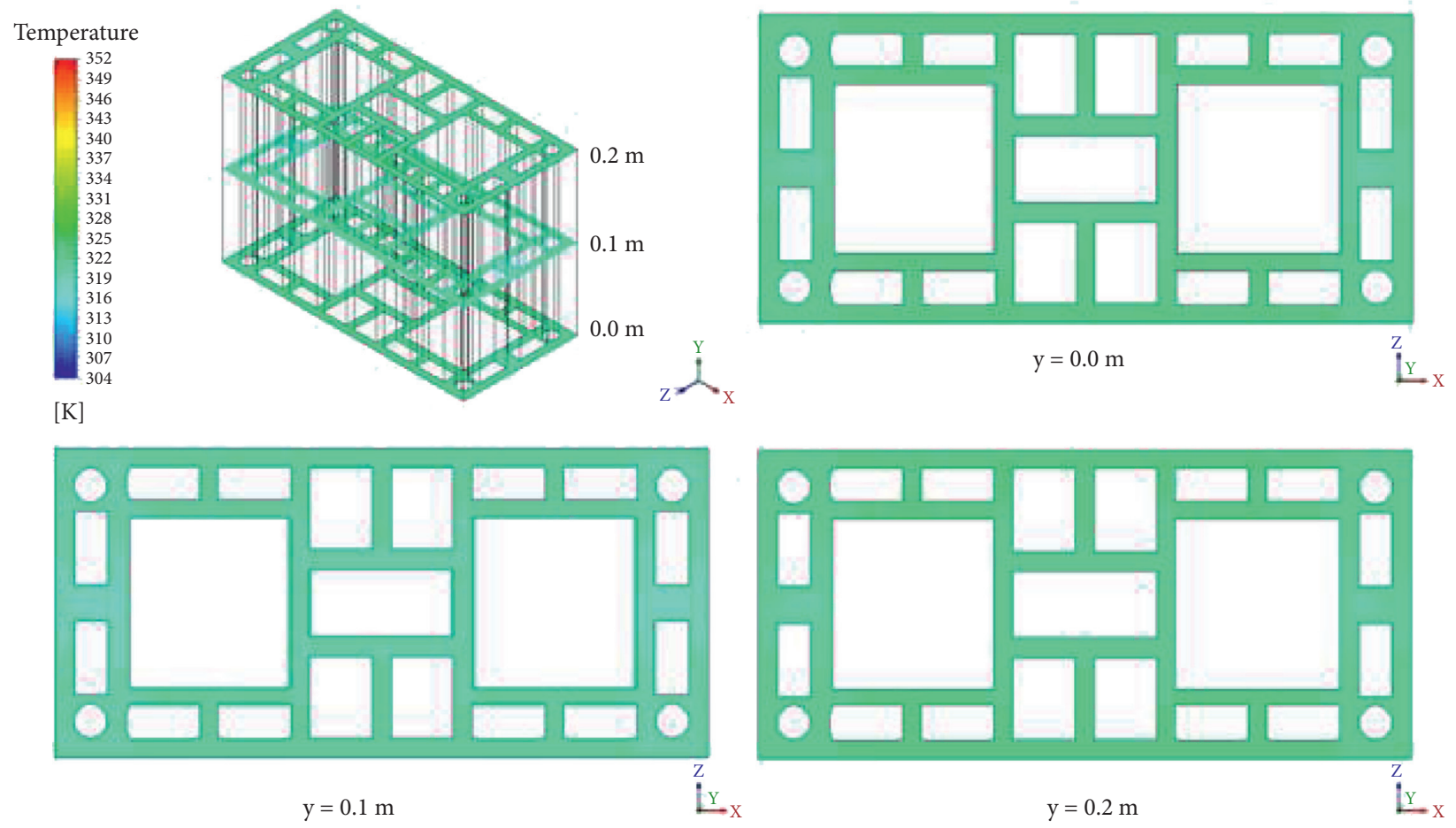

Figure 12: Temperature field inside the brick at different $X Z$ planes, with the elapsed time of 60 minutes $\left(T=80^{\circ} \mathrm{C}, \mathrm{RH}=5 \%\right)$.
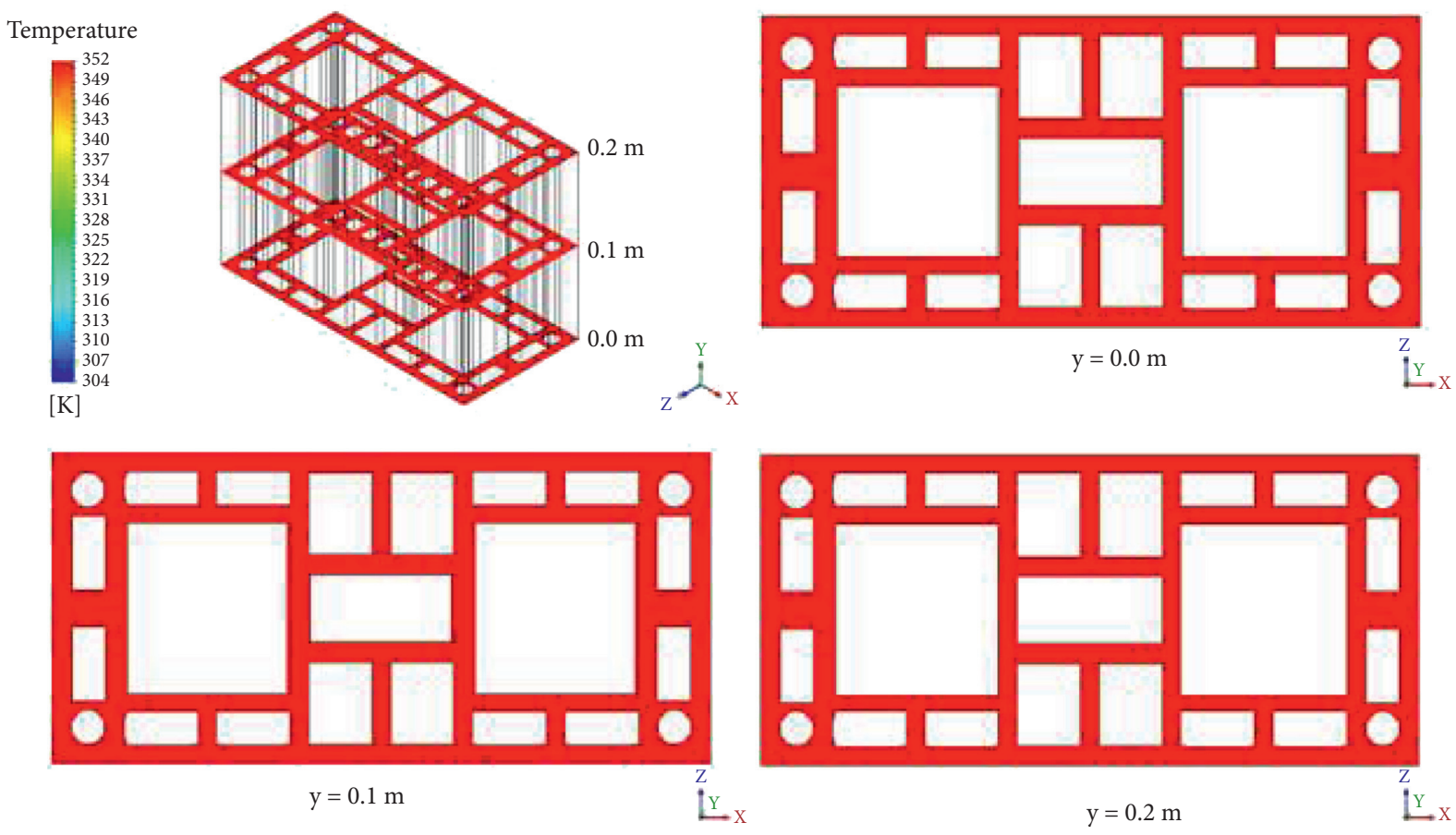

Figure 13: Temperature field inside the brick at different $X Z$ planes, with the elapsed time of 15.5 hours $\left(T=80^{\circ} \mathrm{C}, \mathrm{RH}=5 \%\right)$.

and governing equation and boundary conditions considered in the modeling. Tables 9 and 10 summarize some values of the transport coefficients obtained by Silva [3], in an experimental research with industrial hollow ceramic bricks dried at different temperatures, and the experimental values obtained by Brito [10] and Nascimento [26], with common solid clay brick (parallelepiped shape), also, obtained at different temperatures. However, it should be mentioned that Fick's second law of diffusion was used in all cited works.

The practical importance of studying drying of one particle has severe restriction because the materials are usually dried in thick layers: stationary or in motion and related to several particles. In the dryer study, the models 

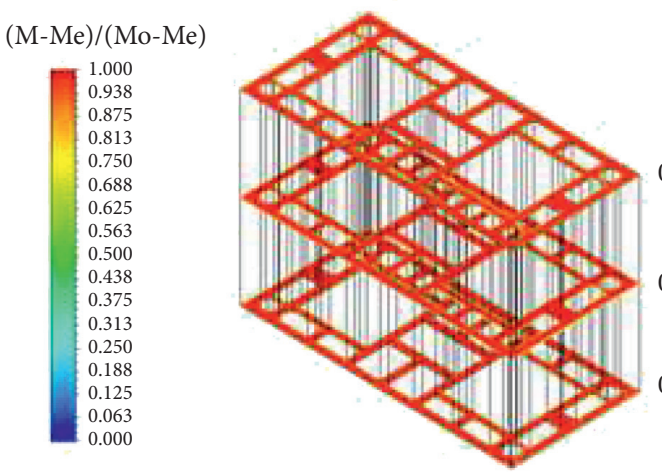

$0.2 \mathrm{~m}$

$0.1 \mathrm{~m}$

$0.0 \mathrm{~m}$
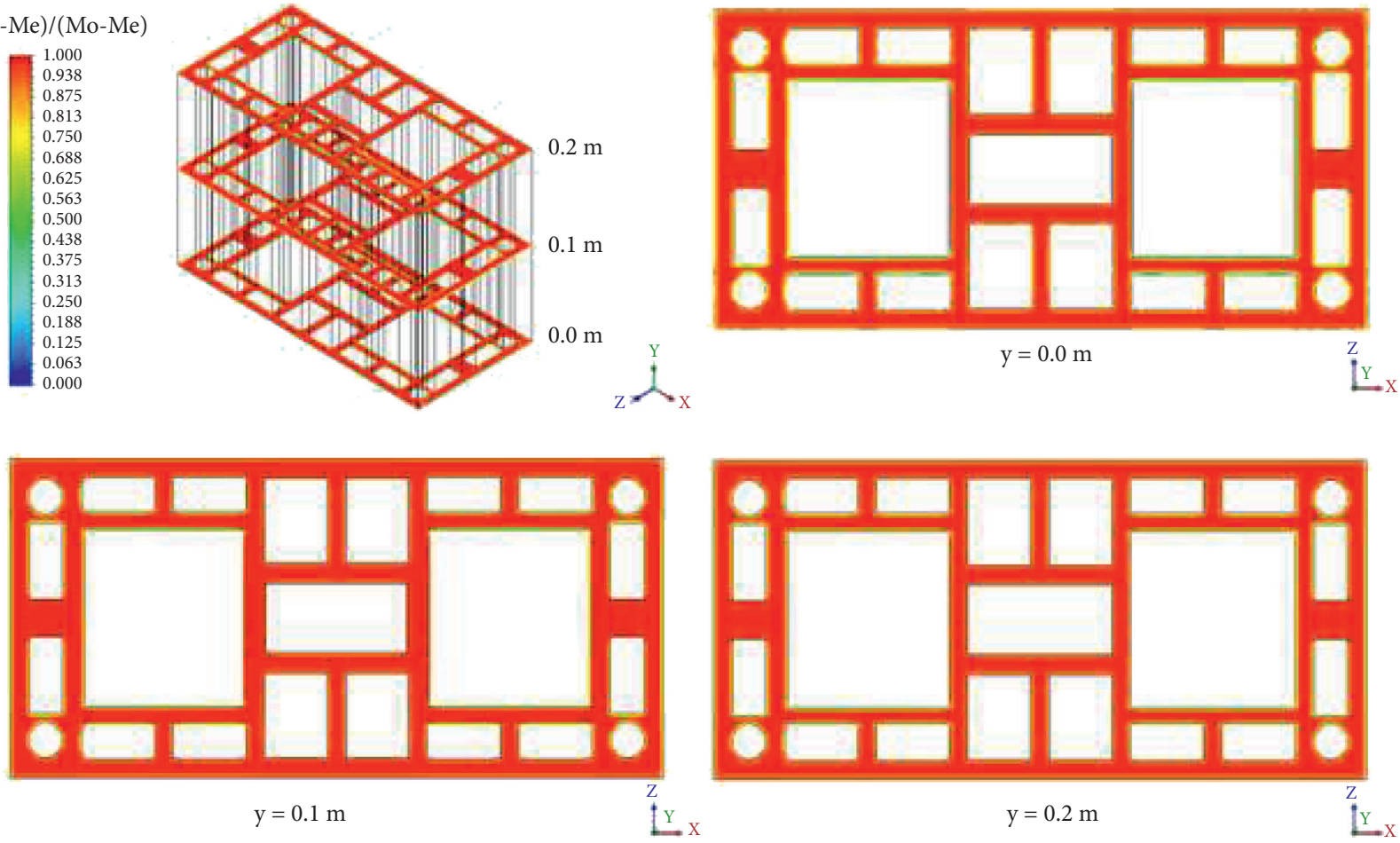

Figure 14: Dimensionless moisture field in the brick, at different planes $X Z$ with the elapsed time of 10 minutes $\left(T=80^{\circ} \mathrm{C}, \mathrm{RH}=5 \%\right)$.
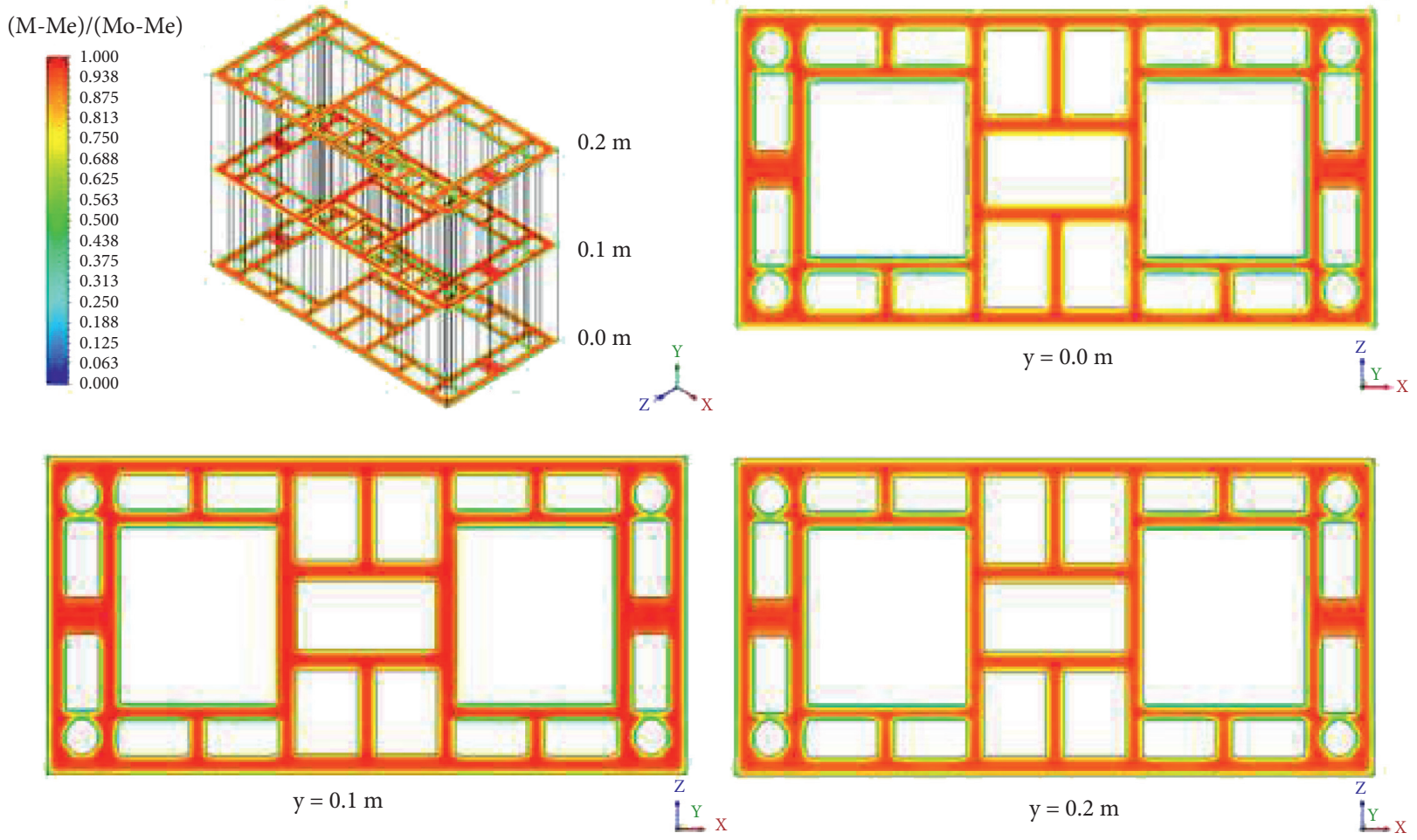

Figure 15: Dimensionless moisture field in the brick, at different planes $X Z$ with the elapsed time of 30 minutes $\left(T=80^{\circ} \mathrm{C}, \mathrm{RH}=5 \%\right)$.

mostly used take into account mass and energy balance between the product and air in the dryer and, thus, are more complete mathematical formulations. Despite the present research is related for one brick and to the used particle level models in the analysis, these models are important and can be used to complete thick layer models (dryer level models) as auxiliary equations for heat and mass balance in the product as reported in the literature $[11,18]$. 

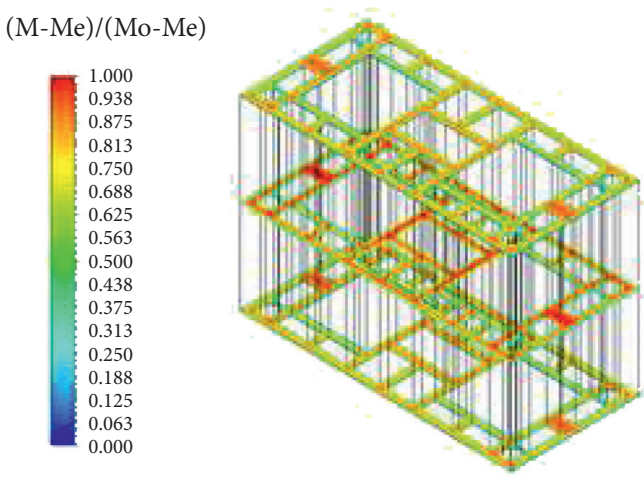

$0.2 \mathrm{~m}$

$0.1 \mathrm{~m}$

$0.0 \mathrm{~m}$
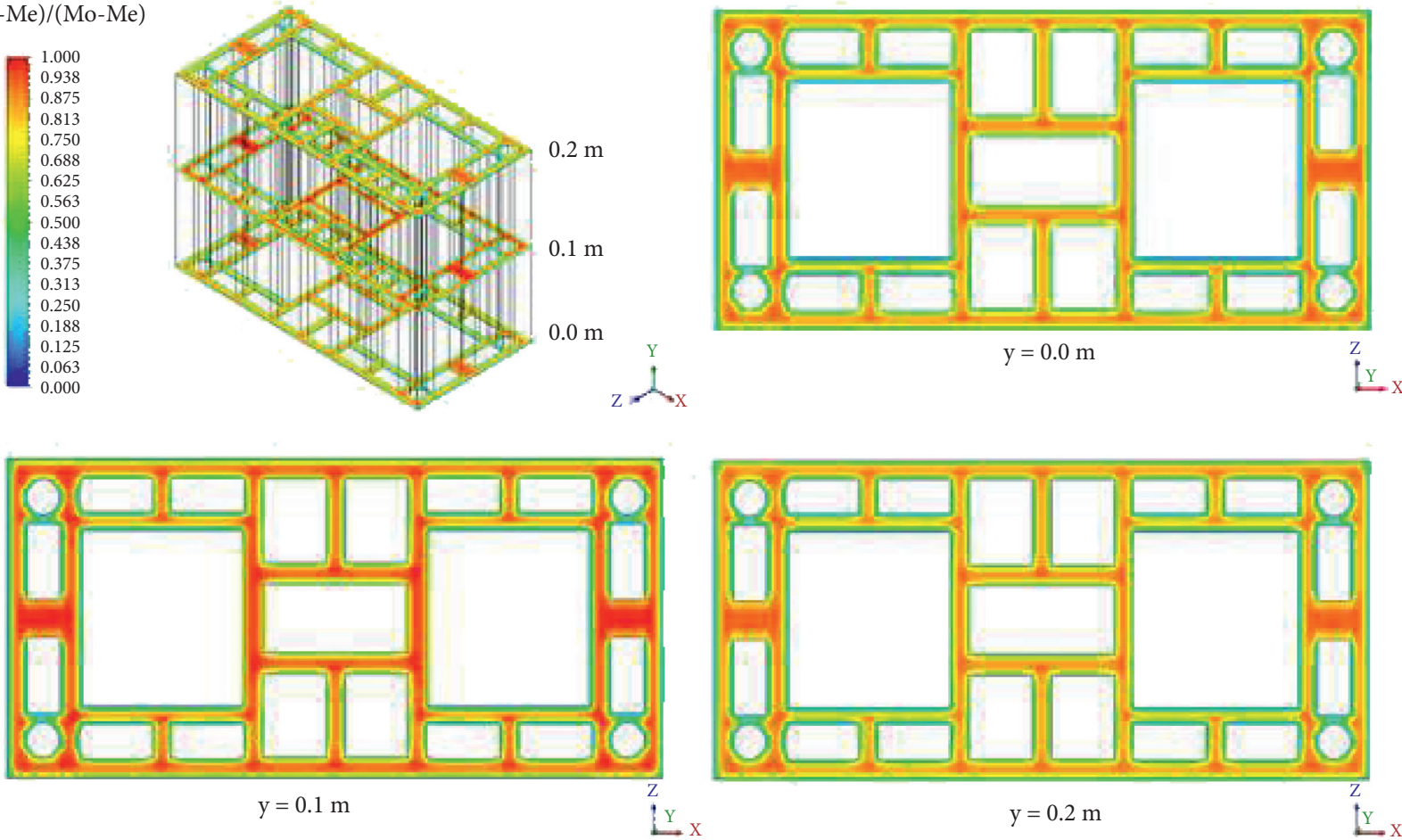

Figure 16: Dimensionless moisture field in the brick, at different planes $X Z$ with the elapsed time of 60 minutes $\left(T=80^{\circ} \mathrm{C}, \mathrm{RH}=5 \%\right)$.
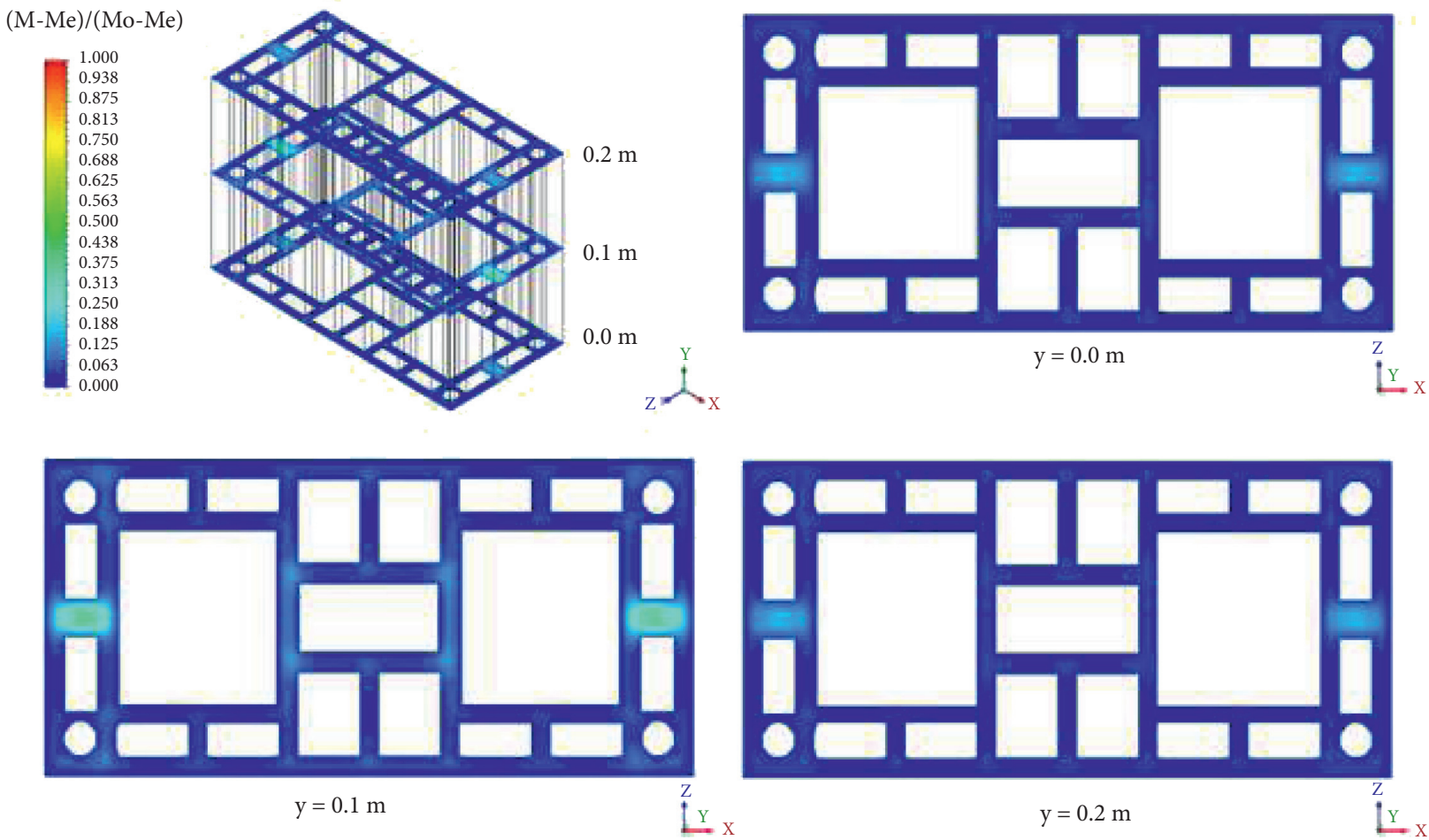

Figure 17: Dimensionless moisture field in the brick, at different planes $X Z$ with the elapsed time of 15.5 hours $\left(T=80^{\circ} \mathrm{C}, \mathrm{RH}=5 \%\right)$. 
TABLE 7: Values of mass transport coefficients estimated numerically.

\begin{tabular}{lccccc}
\hline \multirow{2}{*}{$\left({ }^{\circ} \mathrm{C}\right)$} & \multicolumn{2}{c}{ Process parameter } & \multicolumn{2}{c}{ Statistical parameters } \\
& $D_{s}\left(\mathrm{~m}^{2} / \mathrm{s}\right)$ & $h_{m}(\mathrm{~m} / \mathrm{s})$ & $\mathrm{ERMQ}_{\mathrm{M}}(\mathrm{kg} / \mathrm{kg})^{2}$ & $\bar{S}_{M}^{2}(\mathrm{~kg} / \mathrm{kg})^{2}$ & Pearson correlation coefficient $(R)$ \\
\hline 50 & $6 \times 10^{-10}$ & $1 \times 10^{+30}$ & 0.001424 & 0.000043 & 0.997 \\
60 & $7 \times 10^{-10}$ & $1 \times 10^{+30}$ & 0.002431 & 0.000078 & 0.995 \\
70 & $8 \times 10^{-10}$ & $1 \times 10^{+30}$ & 0.002742 & 0.000091 & 0.994 \\
80 & $9 \times 10^{-10}$ & $1 \times 10^{+30}$ & 0.003255 & 0.000112 & 0.992 \\
90 & $10 \times 10^{-10}$ & $1 \times 10^{+30}$ & 0.004452 & 0.000154 & 0.989 \\
100 & $12 \times 10^{-10}$ & $1 \times 10^{+30}$ & 0.004404 & 0.000169 & 0.988 \\
\hline
\end{tabular}

TABLE 8: Values of heat transport coefficients estimated numerically.

\begin{tabular}{|c|c|c|c|c|}
\hline \multirow{2}{*}{$\mathrm{T}\left({ }^{\circ} \mathrm{C}\right)$} & \multirow{2}{*}{$\begin{array}{c}\text { Process parameter } \\
h_{\mathrm{c}}\left(\mathrm{W} / \mathrm{m}^{2} \cdot \mathrm{K}\right)\end{array}$} & \multicolumn{3}{|c|}{ Statistical parameters } \\
\hline & & $\mathrm{ERMQ}_{\mathrm{T}}\left({ }^{\circ} \mathrm{C}\right)^{2}$ & $\bar{S}_{T}^{2}\left({ }^{\circ} \mathrm{C}\right)^{2}$ & Pearson correlation coefficient $(R)$ \\
\hline 50 & 1 & 273.79 & 8.30 & 0.990 \\
\hline 60 & 1 & 377.92 & 12.19 & 0.949 \\
\hline 70 & 1 & 1354.59 & 45.15 & 0.943 \\
\hline 80 & 1 & 353.59 & 12.19 & 0.980 \\
\hline 90 & 1 & 511.38 & 17.63 & 0.982 \\
\hline 100 & 1 & 691.95 & 26.61 & 0.988 \\
\hline
\end{tabular}

TABLE 9: Mass diffusion coefficient of clay brick at different drying conditions as reported in the literature.

\begin{tabular}{|c|c|c|c|c|c|c|c|c|}
\hline \multirow{2}{*}{ Material } & \multicolumn{7}{|c|}{$D_{s} \times 10^{+10}\left(\mathrm{~m}^{2} / \mathrm{s}\right)$} & \multirow{2}{*}{ Source } \\
\hline & $50^{\circ} \mathrm{C}$ & $60^{\circ} \mathrm{C}$ & $70^{\circ} \mathrm{C}$ & $80^{\circ} \mathrm{C}$ & $90^{\circ} \mathrm{C}$ & $100^{\circ} \mathrm{C}$ & $110^{\circ} \mathrm{C}$ & \\
\hline Common clay brick & - & 23.3 & - & 129.6 & - & - & 152.0 & {$[26]$} \\
\hline Common clay brick & - & 22.0 & - & 141.0 & - & - & 210.0 & {$[10]$} \\
\hline Industrial clay brick (holed) & 4.0 & 0.3 & 0.9 & 8.0 & 10.0 & 16.0 & - & {$[3]$} \\
\hline
\end{tabular}

TABLE 10: Convective mass transfer coefficient of clay brick at different drying conditions as reported in the literature.

\begin{tabular}{|c|c|c|c|c|c|c|c|c|}
\hline \multirow{2}{*}{ Material } & \multicolumn{7}{|c|}{$h_{m}\left(\mathrm{~m}^{2} / \mathrm{s}\right)$} & \multirow{2}{*}{ Source } \\
\hline & $50^{\circ} \mathrm{C}$ & $60^{\circ} \mathrm{C}$ & $70^{\circ} \mathrm{C}$ & $80^{\circ} \mathrm{C}$ & $90^{\circ} \mathrm{C}$ & $100^{\circ} \mathrm{C}$ & $110^{\circ} \mathrm{C}$ & \\
\hline Common clay brick & - & $1.65 \times 10^{-6}$ & - & $1.35 \times 10^{-6}$ & - & - & $1.82 \times 10^{-6}$ & {$[26]$} \\
\hline Common clay brick & - & $1.65 \times 10^{-6}$ & - & $1.35 \times 10^{-6}$ & - & - & $1.82 \times 10^{-6}$ & {$[10]$} \\
\hline Industrial holed clay brick & $1 \times 10^{+30}$ & $1 \times 10^{+30}$ & $1 \times 10^{+30}$ & $1 \times 10^{+30}$ & $1 \times 10^{+30}$ & $1 \times 10^{+30}$ & - & [3] \\
\hline
\end{tabular}

\section{Conclusions}

In this work, the numerical results were presented of the drying and heating kinetics, moisture content, and temperature fields inside the hollow ceramic brick at different elapsed times. In accordance with the predicted results, the following can be concluded:

(a) The mathematical model proposed and described was adequate to describe the drying process with numerical values of temperature and moisture content at different times in concordance with the experimental data.

(b) The heating and moisture removal rates are faster for higher values of drying-air temperature and lower relative humidity values.

(c) The results showed that the ceramic brick regions near the vertices present lower values of moisture content and higher values of temperature than the interior in consequence of the highest values of temperature and moisture gradients observed near the vertices.

(d) The temperature and moisture content fields inside the brick have shown a strong dependence with the drying-air conditions.

(e) The moisture content and temperature fields allow to verify the brick regions with deformations and cracks (reducing the product quality in a drying process) as in these regions it is possible to observe high values of hydric and thermal gradients.

(f) The increase of the variable drying-air temperature implies an increase of the effective mass diffusion coefficient.

\section{Data Availability}

The data used to support the findings of this study are available from A.G. Barbosa de Lima (antonio.gilson@ ufcg.edu.br). 


\section{Conflicts of Interest}

The authors declare that they have no conflicts of interest.

\section{Acknowledgments}

The authors thank CAPES, CNPq, FINEP (Brazilian Research Agencies), and Federal Rural University of the SemiArid Region (UFERSA) for the financial support. This study was also supported by Base Funding (UIDB/04708/2020) and Programmatic Funding (UIDP/04708/2020) of the CONSTRUCT-Instituto de I\&D em Estruturas e Constru cões funded by national funds through the FCT/MCTES (PIDDAC).

\section{References}

[1] W. D. Callister, Materials Science and Engineering: An Introduction, John Wiley \& Sons, Hoboken, NJ, USA, 2007.

[2] W. D. Callister and D. G. Rethwisch, Fundamentals of Materials Science and Engineering: An Integrated Approach, John Wiley \& Sons, Hoboken, NJ, USA, 2008.

[3] J. B. Silva, Simulation and Experimentation of the Drying of Hollow Ceramic Bricks, Ph.D. Thesis, Federal University of Campina Grande, Campina Grande, Brazil, 2009.

[4] M. H. F. Medeiros, D. J. Souza, J. H. Filho, C. S. Adorno, V. A. Quarcioni, and E. Pereira, "Red-clay waste and limestone filler added in Portland cement composite: effects on sulfate attack and alkali-silica reaction," Materialséria, vol. 21, no. 2, pp. 282-300, 2016.

[5] A. M. Vasconcelos da Silva, J. M. P. Q. Delgado, A. S. Guimarães et al., "Industrial ceramic blocks for buildings: clay characterization and drying experimental study," Energies, vol. 13, no. 11, p. 2834, 2020.

[6] J. J. S. Nascimento, F. A. Belo, and A. G. B. de Lima, "Experimental drying of ceramics bricks including shrinkage," Defect and Diffusion Forum, vol. 365, pp. 106-111, 2015.

[7] W. P. da Silva, C. M. D. P. da Silva e Silva, L. D. da Silva, and V. S. d. O. Farias, "Drying of clay slabs: experimental determination and prediction by two-dimensional diffusion models," Ceramics International, vol. 39, no. 7, pp. 7911-7919, 2013.

[8] Y. Itaya, S. Taniguchi, and M. Hasatani, "A numerical study of transient deformation and stress behavior of a clay slab during Drying," Drying Technology, vol. 15, no. 1, pp. 1-21, 1997.

[9] G. S. Almeida, F. V. S. Tavares, W. M. P. B. Lima, and A. G. Barbosa de Lima, "Energetic and exergetic analysis of the clay bricks drying in an industrial tunnel dryer," Defect and Diffusion Forum, vol. 369, pp. 104-109, 2016.

[10] M. K. T. Brito, "Theoretical Study of Heat and Mass Transfer on the Ceramic Bricks Drying with Paralelepipedic Shape," M.Sc. Thesis, Federal University of Campina Grande, Campina Grande, Brazil, 2016.

[11] G. da Silva Almeida, J. Barbosa da Silva, C. Joaquina e Silva, R. Swarnakar, G. de Araújo Neves, and A. G. Barbosa de Lima, "Heat and mass transport in an industrial tunnel dryer: modeling and simulation applied to hollow bricks," Applied Thermal Engineering, vol. 55, no. 1-2, pp. 78-86, 2013.

[12] M. V. Araújo, R. S. Santos, R. M. da Silva, J. B. S. do Nascimento, W. R. Gomes dos Santos, and A. G. B. de Lima, "Drying of industrial hollow ceramic brick: a numerical analysis using CFD," Defect and Diffusion Forum, vol. 391, pp. 48-53, 2019.
[13] M. V. Araújo, R. S. Santos, R. M. da Silva, and A. G. Barbosa de Lima, "Drying of industrial hollow ceramic brick: analysis of the moisture content and temperature parameters," Defect and Diffusion Forum, vol. 380, pp. 72-78, 2017.

[14] I. O. Martins, M. B. Quadri, V. P. Nicolau, and F. Miotto, "Simulation of the convective drying of a red clay brick," in Proceedings of the XXI Brazilian Congress of Chemical Engineering, Fortaleza, Brazil, January, 2016.

[15] M. V. Araújo, B. R. B. Correia, V. A. A. Brandão et al., "Convective drying of ceramic bricks by CFD: transport phenomena and process parameters analysis," Energies, vol. 13, no. 8, p. 2020, 2073.

[16] G. Musielak and T. Śliwa, "Modeling and numerical simulation of clays cracking during drying," Drying Technology, vol. 33, no. 14, pp. 1758-1767, 2015.

[17] M. Simo-Tagne, R. Rémond, Y. Rogaume, A. Zoulalian, and B. Bonoma, "Modeling of coupled heat and mass transfer during drying of tropical woods," International Journal of Thermal Sciences, vol. 109, no. November, pp. 299-308, 2016.

[18] E. S. Lima, W. M. P. B. Lima, A. G. Barbosa de Lima, S. R. Farias Neto, E. G. Silva, and V. A. B. Oliveira, "Advanced study to heat and mass transfer in arbitrary shape porous materials: foundations, phenomenological lumped modeling and applications," in Transport Phenomena in Multiphase Systems, J. M. P. Q. Delgado and A. G. Barbosa de Lima, Eds., vol. 93, Cham, Switzerland, Springer International Publishing, 2018.

[19] I. B. Celik, "Procedure for estimation and reporting of uncertainty due to discretization in CFD applications," Journal of Fluids Engineering, vol. 130, no. 7, Article ID 078001, 2008.

[20] P. J. Roache, "Manual Ansys CFX - Reference Guide," Ansys Inc., Canonsburg, PA, USA, 2015.

[21] R. S. Santos, S. R. de Farias Neto, A. G. Barbosa de Lima, J. B. Silva Júnior, and A. M. V. da Silva, "Drying of ceramic bricks: thermal and mass analysis via CFD," Diffusion Foundations, vol. 25, pp. 133-153, 2020.

[22] Y. A. Çengel and J. J. Ghajar, "Heat and Mass Transfer: A Practical Approach,” McGraw-Hill, New york, NY, USA, 2012.

[23] S. Paudel and N. Saenger, "Grid refinement study for three dimensional CFD model involving incompressible free surface flow and rotating object," Computers \& Fluids, vol. 143, pp. 134-140, 2017.

[24] P. J. Roache, "Perspective: a Method for uniform reporting of grid refinement studies," Journal of Fluids Engineering, vol. 116, no. 3, pp. 405-413, 1994.

[25] I. C. O. Karatekin, "Numerical experiments on application of Richarson extrapolation with nonuniform grids," ASME Journal of Fluid Engineering, vol. 119, pp. 584-590, 1997.

[26] J. J. S. Nascimento, Transient Diffusion Phenomena in Paralelepiped Solids. Cases Studies: Drying of Ceramic Materials, PhD Thesis, Federal University of Paraíba. João Pessoa, Brazil, 2002. 